\title{
Effect of the nonlinear displacement-dependent characteristics of a hydraulic damper on high-speed rail pantograph dynamics
}

\author{
Wenlin Wang ${ }^{\mathrm{a}, \mathrm{b}, \mathrm{c}^{*}}$, Yuwen Liang $^{\mathrm{b}}$, Weihua Zhang ${ }^{\mathrm{c}}$, Simon Iwnicki ${ }^{\mathrm{d}}$ \\ ${ }^{\text {a }}$ School of Mechanical Engineering, Dongguan University of Technology, Dongguan 523808, P. R. of China \\ ${ }^{\mathrm{b}}$ College of Mechanical and Vehicle Engineering, Hunan University, Changsha 410082, P. R. of China \\ ${ }^{c}$ State Key Laboratory of Traction Power, Southwest Jiaotong University, Chengdu 610031, China \\ ${ }^{\mathrm{d}}$ Institute of Railway Research, University of Huddersfield, Huddersfield HD1 3DH, UK
}

\begin{abstract}
A new simplified-parametric model is proposed to describe the nonlinear displacementdependent damping characteristics of a railway pantograph hydraulic damper and validated by the experimental results in this study. Then, a full mathematical model of the pantograph-catenary system, which incorporates the new pantograph damper model, is established to simulate the effect of the damping characteristics on the pantograph dynamics. The simulation results show that large $F_{\text {const }}$ and $C_{0}$ in the pantograph damper model can improve both the raising performance and contact quality of the pantograph, whereas a large $C_{0}$ has no obvious effect on the lowering time of the pantograph; the nonlinear damping characteristics described by the second item in the new damper model have dominating effects on the total lowering time, maximum acceleration and maximum impact acceleration of the pantograph. Thus, within the constraint of total lowering time, increasing the second item damping characteristics of the damper will obviously improve the lowering performance of the pantograph and reduce excessive impact between the pantograph and its base frame. The proposed concise pantograph hydraulic damper model appears to be more complete and accurate than the previous single-parameter model, so it is more useful in the context of pantograph-catenary dynamics simulation and further parameter optimizations. The obtained simulation results are also valuable and instructive for further optimal specification of railway pantograph hydraulic dampers.
\end{abstract}

Keywords: Pantograph hydraulic damper; displacement-dependent; nonlinear damping characteristics; pantograph-catenary dynamics; contact quality; raising and lowering performance

\section{Introduction}

The pantograph is a key device in the current collection by modern high-speed rail vehicles [1]; an optimal design of the structural and component parameters of the pantograph will improve the pantograph-

\footnotetext{
* Corresponding author at: School of Mechanical Engineering, Dongguan University of Technology, Dongguan 523808, Guangdong Province, PR China. Tel.: +86 76922861122.

E-mail address: pianowwl@163.com (Wenlin Wang).
} 
catenary interaction and enable more stable current collection. A hydraulic damper is often installed between the base frame and the lower arm mechanism of a pantograph, as illustrated in Fig. 1. When the pantograph is lowered, the damper is extended; when the pantograph is raised, the damper is compressed. The hydraulic damper is a crucial component in improving the pantograph-catenary interaction quality and obtaining the ideal raising and lowering performance of the pantograph.

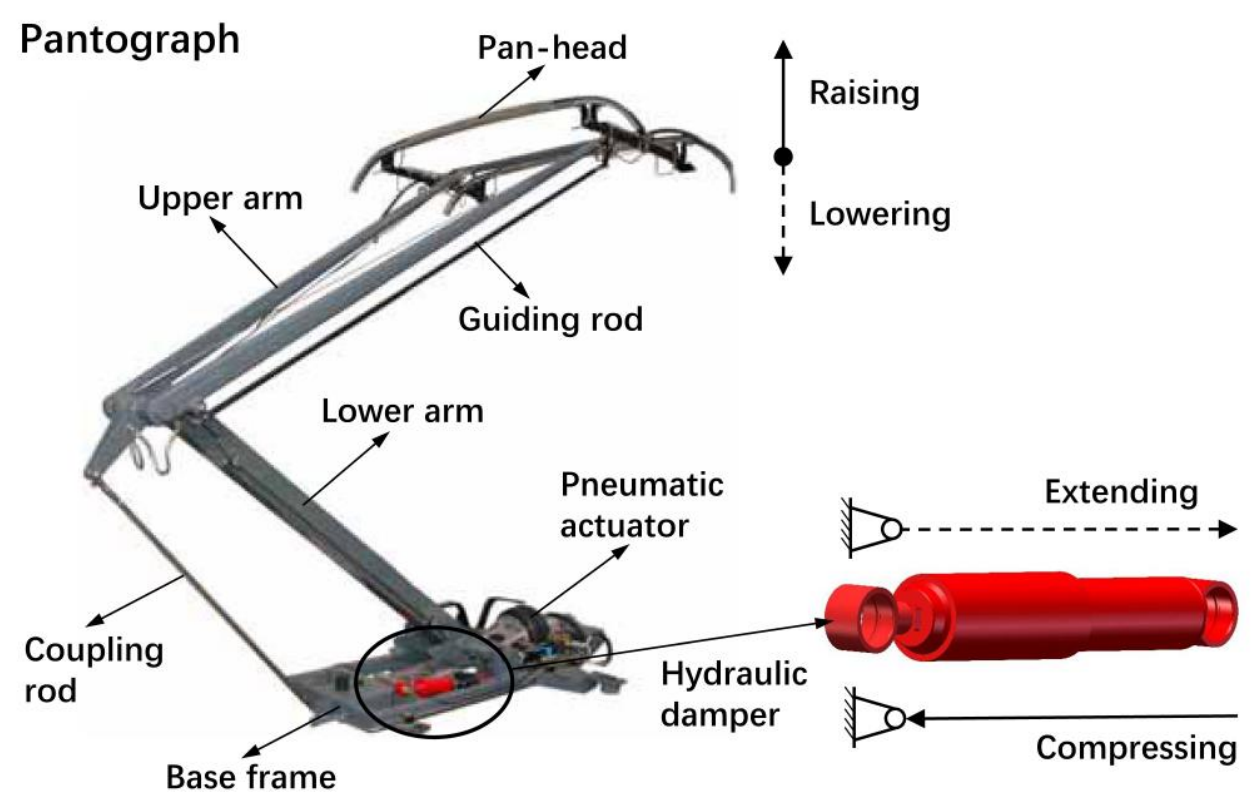

Fig. 1 A simple illustration of the motions of a high-speed rail pantograph and its hydraulic damper

Previous studies have been performed to model the nonlinear characteristics of railway hydraulic dampers and analyse their effects on the yaw motion, stability [2-4] and riding comfort [5] of rail vehicle systems. Oh, et al. [6] introduced magneto-rheological dampers in the semi-active control of the rail vehicle secondary suspension. Stein, et al. [7] used an adjustable damper in the seat suspension of a locomotive driver to reduce fatigue and pursue better comfort of the locomotive driver. Croft, et al. [8] modelled and predicted the effect of rail dampers on the wheel-rail interaction and rail roughness growth.

Pombo and Ambrósio [9] studied the effects of the pan-head mass, pan-head suspension stiffness and base frame damping on the pantograph-catenary interaction quality by establishing a lumped-mass linear dynamic model of the pantograph. In the pantograph model, the hydraulic damper was considered a single-parameter linear model with the damping coefficient as the only parameter. In many similar studies, in both lumped-mass [10-15] and multibody [16-18] pantograph models, the hydraulic damper was treated as a single-parameter model.

Zhou and Zhang [19] optimized the pantograph parameters using the sensitivity analysis and experience, and the optimal results were experimentally validated. Similar design optimizations [20-23] of the 
pantograph parameters were performed using automatic algorithms or robust design techniques. However, in these works, the pantograph models are almost lumped-mass linear ones, where the hydraulic damper is also considered a single-parameter model.

Thus:

(1) Research on modelling the nonlinear displacement-dependent characteristics of the pantograph hydraulic damper is notably limited.

(2) In current studies on the pantograph-catenary interaction and parameter design optimization of the pantograph and catenary system, the hydraulic damper was considered a single-parameter linear model. The single-parameter linear model is notably different from the actual nonlinear displacement-dependent characteristics. In addition, during the raising or lowering process of the pantograph, the damper angle changes with the motion of the framework, so there is the problem of effective damping. Thus, the current damper model appears incomplete, and the accuracy must be improved.

(3) Most existing works concern the problems of the pantograph-catenary interaction, but the effect of component characteristics, e.g., the hydraulic damper characteristics, on the raising and lowering performance of the pantograph is hardly addressed.

In this work, a new simplified-parametric model is proposed to describe the nonlinear displacementdependent damping characteristics of the pantograph hydraulic damper and validated by experimental results. Then, a full mathematical model of the pantograph-catenary system, which incorporates the new pantograph damper model, is established to simulate the effect of the damping characteristics on the pantograph dynamics, and valuable results are obtained. The concise pantograph hydraulic damper model appears to be more complete and accurate than previous single-parameter model, so it is more useful in the context of pantograph-catenary dynamics simulation and parameter optimization. The obtained simulation results are also valuable and instructive for further optimal specification of pantograph hydraulic dampers.

The paper is structured as follows: a full mathematical modelling of the pantograph-catenary system with a new damper model is performed in Section 2, the effect of the damper characteristics on the pantograph dynamics is simulated in Section 3, and conclusions are drawn in the final section.

\section{Mathematical modeling of the pantograph-catenary system with a new damper model}

Figure 2 schematically illustrates the configuration, geometry and parameters of the pantographcatenary system. The structures of the upper arm, lower arm, guiding rod, coupling rod and hydraulic damper are considered a united multibody mechanism, i.e., the framework; the pantograph head includes mass $m_{\mathrm{h}}$ and a suspension with stiffness $k_{\mathrm{h}}$ and damping $c_{\mathrm{h}}$; the pantograph head is connected with the framework by joint $E$. The moving pantograph-catenary interaction is simplified as a variable stiffness $k_{\mathrm{c}}$, 


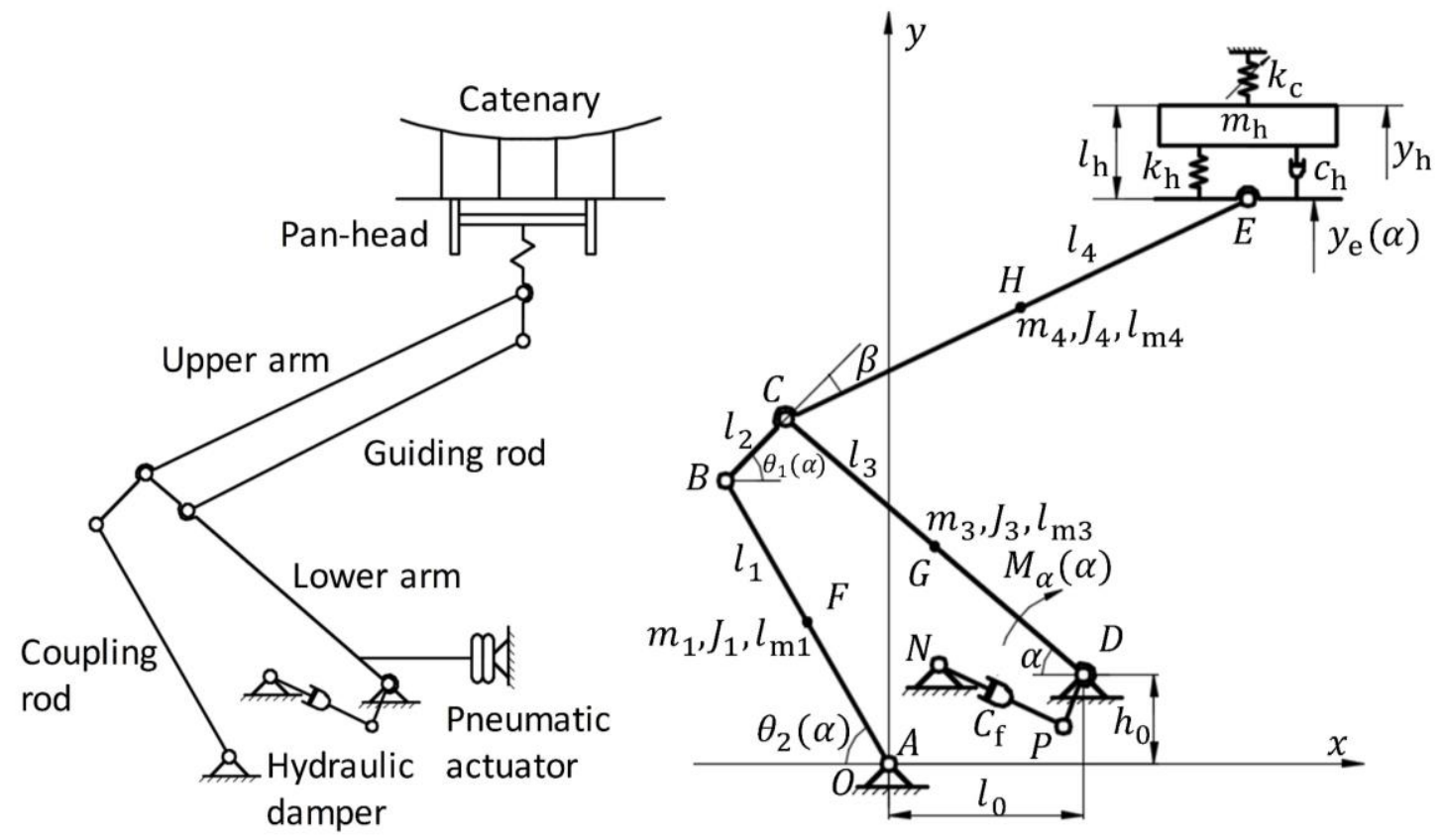

Fig. 2 Schematic illustrations of the configuration (a), geometry and parameters (b) of the pantograph-catenary system so the dynamic interaction force between the pan-head and the catenary can be readily obtained.

\subsection{Multibody dynamic model of the pantograph framework}

\subsubsection{Relations among key kinematic parameters}

To model the multibody dynamics of the pantograph framework, it is necessary to first deduce the kinematic relations among the components of the framework. Using the parameters and coordinates in Fig. 2(b) and only considering the vertical motion of the pantograph, it is easy to deduce the positions and angles of all nodes in the framework in terms of raising angle $\alpha$ of the lower arm.

For example, the raising angle of the coupling rod in terms of $\alpha$ can be formulated by

$\theta_{2}(\alpha)=2 \arctan \frac{k_{2}+\sqrt{-k_{1}^{2}+k_{2}^{2}+k_{3}^{2}}}{k_{1}+k_{3}}$

where

$\left\{\begin{array}{l}k_{1}=l_{2}^{2}-l_{1}^{2}-l_{3}^{2}-h_{0}{ }^{2}-l_{0}{ }^{2}+2 l_{0} l_{3} \cos \alpha-2 h_{0} l_{3} \sin \alpha \\ k_{2}=-2 l_{1} l_{3} \sin \alpha-2 h_{0} l_{1} \\ k_{3}=-2 l_{1} l_{3} \cos \alpha+2 l_{0} l_{1}\end{array}\right.$

and the raising angle of the connection rod $B C$ in terms of $\alpha$ can also be written as 
$\theta_{1}(\alpha)=\arctan \frac{-l_{1} \sin \theta_{2}+h_{0}+l_{3} \sin \alpha}{l_{1} \cos \theta_{2}+l_{0}-l_{3} \cos \alpha}$

The displacement of joint $E$, which is also a crucial parameter, can be deduced as follows

$y_{\mathrm{e}}(\alpha)=h_{0}+l_{3} \sin \alpha+l_{4} \sin \left(\theta_{1}-\beta\right)$

\subsubsection{Multibody dynamic model of the pantograph framework}

In Fig. 2(b), all rods are considered rigid bodies; because the masses of the guiding rod and connection rod $B C$ are small, the guiding rod is negligible, and the connection rod $B C$ can be considered a rod with no mass and no moment of inertia. Thus, the multibody dynamics of the pantograph framework can be described by the following Lagrange differential equation

$\frac{d}{d t}\left(\frac{\partial L}{\partial \dot{\alpha}}\right)-\frac{\partial L}{\partial \alpha}=G_{\mathrm{F}}$

where $L$ is the Lagrangian function and $L=T-U$; $T$ is the kinetic energy of the framework; $U$ is the potential energy of the framework when the potential energy in the plane across point A is considered to be zero.

Thus, according to Fig. 2(b), we obtain

$T=\frac{1}{2} J_{1} \dot{\theta}_{2}^{2}+\frac{1}{2} J_{3} \dot{\alpha}^{2}+\frac{1}{2} J_{4} \dot{\theta}_{1}^{2}+\frac{1}{2} m_{4}\left[l_{3}^{2} \dot{\alpha}^{2}+2 l_{3} l_{\mathrm{m} 4} \dot{\alpha} \dot{\theta}_{1} \cos \left(\alpha+\theta_{1}-\beta\right)\right]$

and

$U=m_{1} g l_{\mathrm{m} 1} \sin \theta_{2}+m_{3} g\left(l_{\mathrm{m} 3} \sin \alpha+h_{0}\right)+m_{4} g\left[h_{0}+l_{3} \sin \alpha+l_{\mathrm{m} 4} \sin \left(\theta_{1}-\beta\right)\right]$

In Eq. (5), $G_{\mathrm{F}}$ is the generalized force, which includes interaction forces from the pantograph head and hydraulic damper and the uplift moment from the pneumatic actuator. According to the principle of virtual work, $G_{\mathrm{F}}$ can be formulated [24] by

$G_{\mathrm{F}}=M_{\alpha}+k_{4}\left[k_{\mathrm{h}}\left(y_{\mathrm{h}}-y_{\mathrm{e}}-l_{\mathrm{h}}\right)+c_{\mathrm{h}}\left(\dot{y}_{\mathrm{h}}-\dot{y}_{\mathrm{e}}\right)+m_{\mathrm{h}} g\right]-F_{\mathrm{d}} k_{5}$

where coefficients $k_{4}$ and $k_{5}$ are defined as variations of the displacement of joint $E y_{\mathrm{e}}$ to $\alpha$ and hydraulic damper length $s$ to $\alpha$, respectively; $k_{4}$ and $k_{5}$ are written as

$k_{4}=\frac{\delta y_{\mathrm{e}}}{\delta \alpha}, k_{5}=\frac{\delta s}{\delta \alpha}$

Referring to Fig. (3), we can calculate the dynamic damper length $s$ in terms of $\alpha$ in Eq. (9) as follows

$s(\alpha)=\sqrt{\left[x_{\mathrm{d}}+l \cos (\alpha+\gamma)\right]^{2}+\left[y_{\mathrm{d}}+l \sin (\alpha+\gamma)\right]^{2}}$

Thus, we substitute Eqs. (6)-(10) into Eq. (5) to obtain a dynamic model of the framework in terms of $\alpha$

$J_{\mathrm{f}}(\alpha) \ddot{\alpha}+U_{\mathrm{f}}(\alpha) \dot{\alpha}^{2}+C_{\mathrm{f}}(\alpha) \dot{\alpha}+F_{\mathrm{f}}(\alpha)=M_{\alpha}(\alpha)$

where the effective moment of inertia $J_{\mathrm{f}}$ of the framework, coefficient $U_{\mathrm{f}}$, effective damping coefficient $C_{\mathrm{f}}$ of the framework, generalized force $F_{\mathrm{f}}$ of the framework and uplift moment $M_{\alpha}$ from the pneumatic actuator 
can be described as follows

$$
J_{\mathrm{f}}(\alpha)=J_{1} k_{6}^{2}+J_{3}+J_{4} k_{7}^{2}+m_{4}\left[l_{3}^{2}+2 k_{7} l_{3} l_{\mathrm{m} 4} \cos \left(\alpha+\theta_{1}-\beta\right)\right]
$$

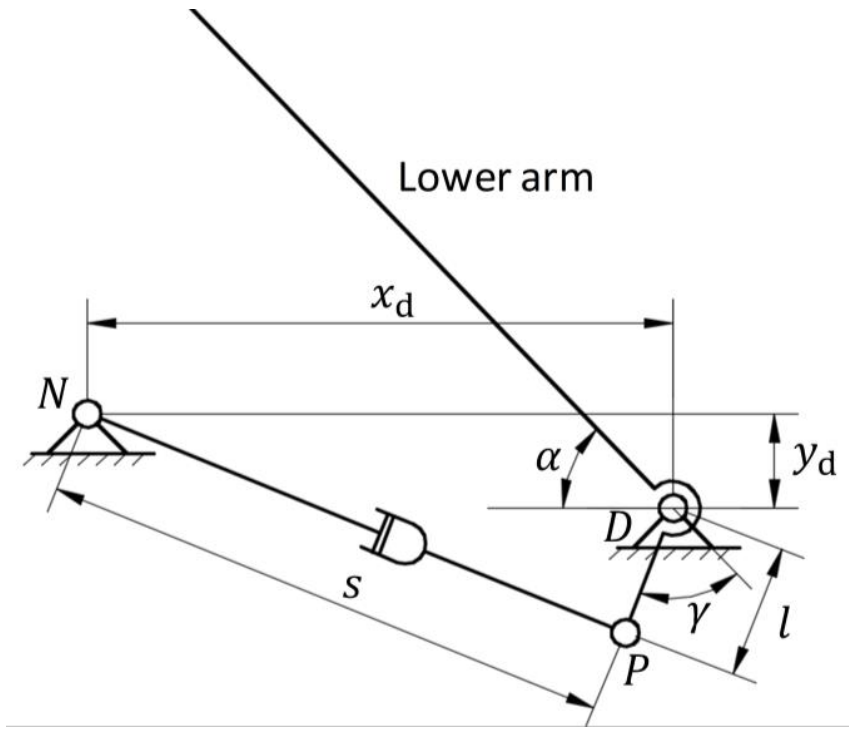

Fig. 3 Geometric parameters to calculate the motion of the hydraulic damper

$$
\begin{aligned}
U_{\mathrm{f}}(\alpha)= & J_{1} k_{6} k_{8}+J_{4} k_{7} k_{9}+m_{4}\left[k_{9} l_{3} l_{\mathrm{m} 4} \cos \left(\alpha+\theta_{1}-\beta\right)-k_{7}\left(1+k_{7}\right) l_{3} l_{\mathrm{m} 4} \sin \left(\alpha+\theta_{1}-\beta\right)\right] \\
C_{\mathrm{f}}(\alpha)= & \frac{d\left(F_{\mathrm{d}} k_{5}\right)}{d \dot{\alpha}} \\
F_{\mathrm{f}}(\alpha)= & m_{1} g l_{\mathrm{m} 1} k_{6} \cos \theta_{2}+m_{3} g l_{\mathrm{m} 3} \cos \alpha+m_{4} g\left[l_{3} \cos \alpha+l_{\mathrm{m} 4} k_{7} \cos \left(\theta_{1}-\beta\right)\right] \\
& +k_{4}\left[k_{\mathrm{h}}\left(y_{\mathrm{h}}-y_{\mathrm{e}}-l_{\mathrm{h}}\right)+c_{\mathrm{h}}\left(\dot{y}_{\mathrm{h}}-\dot{y}_{\mathrm{e}}\right)+m_{\mathrm{h}} g\right] \\
M_{\alpha}(\alpha) & =m_{1} g l_{\mathrm{m} 1} k_{6} \cos \theta_{2}+m_{3} g l_{\mathrm{m} 3} \cos \alpha+m_{4} g\left[l_{3} \cos \alpha+l_{\mathrm{m} 4} k_{7} \cos \left(\theta_{1}-\beta\right)\right]+k_{4}\left(F_{\mathrm{u}}+m_{\mathrm{h}} g\right)
\end{aligned}
$$

where coefficients $k_{6}$ and $k_{7}$ are defined as the variations of the coupling rod raising angle $\theta_{2}$ to $\alpha$ and the angle of the connecting rod $B C$ to horizontal line $\theta_{1}$ to $\alpha$, respectively; $k_{6}$ and $k_{7}$ are written as

$$
k_{6}=\frac{\delta \theta_{2}}{\delta \alpha}, k_{7}=\frac{\delta \theta_{1}}{\delta \alpha}
$$

Coefficients $k_{8}$ and $k_{9}$ are defined as

$$
k_{8}=\frac{d k_{6}}{d \alpha}, k_{9}=\frac{d k_{7}}{d \alpha}
$$

In the pantograph dynamics research, sometimes it is more interesting to study the dynamic model in terms of the displacement of joint $E$, i.e., $y_{\mathrm{e}}$; hence, except for using Eq. (4), it is easy to deduce and use the following relations to transform $\alpha$ to $y_{\mathrm{e}}$

$$
\dot{\alpha}=\frac{1}{k_{4}} \dot{y}_{\mathrm{e}}, \quad \ddot{\alpha}=\frac{1}{k_{4}} \ddot{y}_{\mathrm{e}}+\frac{k_{10}}{k_{4}^{2}} \dot{y}_{\mathrm{e}}^{2}
$$


where coefficient $k_{10}$ is defined as

$k_{10}=-\frac{d k_{4}}{d \alpha}$

2.2. Dynamic model of the pantograph head with catenary interaction

Referring to Fig. 2(b) and according to Newton's second law, the dynamic model of the pantograph head is written as

$m_{\mathrm{h}} \ddot{y}_{\mathrm{h}}=-k_{\mathrm{h}}\left(y_{\mathrm{h}}-y_{\mathrm{e}}-l_{\mathrm{h}}\right)-c_{\mathrm{h}}\left(\dot{y}_{\mathrm{h}}-\dot{y}_{\mathrm{e}}\right)-F_{\mathrm{c}}$

where the pantograph-catenary interaction force $F_{\mathrm{c}}$ can be further written as

$$
F_{\mathrm{c}}= \begin{cases}k_{\mathrm{c}}\left(y_{\mathrm{h}}-y_{\mathrm{c}}\right), & y_{\mathrm{h}} \geq y_{\mathrm{c}} \\ 0, & y_{\mathrm{h}}<y_{\mathrm{c}}\end{cases}
$$

where $k_{\mathrm{c}}$ is the changeable catenary stiffness and given by the following model [25]

$k_{\mathrm{c}}(v, t)=k_{0}\left[1+a_{1} \cos \left(\frac{2 \pi v}{L_{\mathrm{c}}} t\right)+a_{2} \cos \left(\frac{2 \pi v}{L_{\mathrm{d}}} t\right)+a_{3} \cos ^{2}\left(\frac{2 \pi v}{L_{\mathrm{c}}} t\right)+a_{4} \cos ^{2}\left(\frac{\pi v}{L_{\mathrm{c}}} t\right)+a_{5} \cos ^{2}\left(\frac{\pi v}{L_{\mathrm{d}}} t\right)\right]$

Eq. (23) describes the fluctuating stiffness of the catenary in terms of the pantograph moving speed and time; it is a law fitted from the finite element model [25] of the common Chinese catenary.

Thus, as shown in Fig. 2(b), the dynamics of the pantograph head and catenary are coupled by $k_{c}$; the dynamics of the pantograph head and framework are coupled by joint $E$, i.e., the dynamic forces from the pantograph head act on the framework through joint $E$, and in return the framework motions affect the pantograph head also through joint $E$. 


\subsection{Nonlinear displacement-dependent characteristics of the hydraulic damper}

The pantograph damper has nonlinear displacement-dependent damping characteristics. Figs. 1 and 4(a) show that when the pantograph is in the normal working position, the damper has the shortest length, vibrates with very small amplitudes, and provides the pantograph with a small damping.

When the pantograph is lowered, the damper is extended and the fluids in the damper are displaced from the left chamber of the piston to the right chamber of the piston through the orifices in the rod. At the beginning of the extension, the damper produces small damping forces. However, with continuing extension of the damper, the orifices in the rod are sequentially obstructed by the guide seat, and the pressure in the left chamber of the piston increases, so the damper produces notably high damping forces to stop the pantograph to the vehicle roof.

When the pantograph is raised, the damper is compressed and the fluids in the damper are displaced from the inner tube to the reservoir through the foot valve with small resistances. In this process, the damper also provides the pantograph with a small damping.

(a)

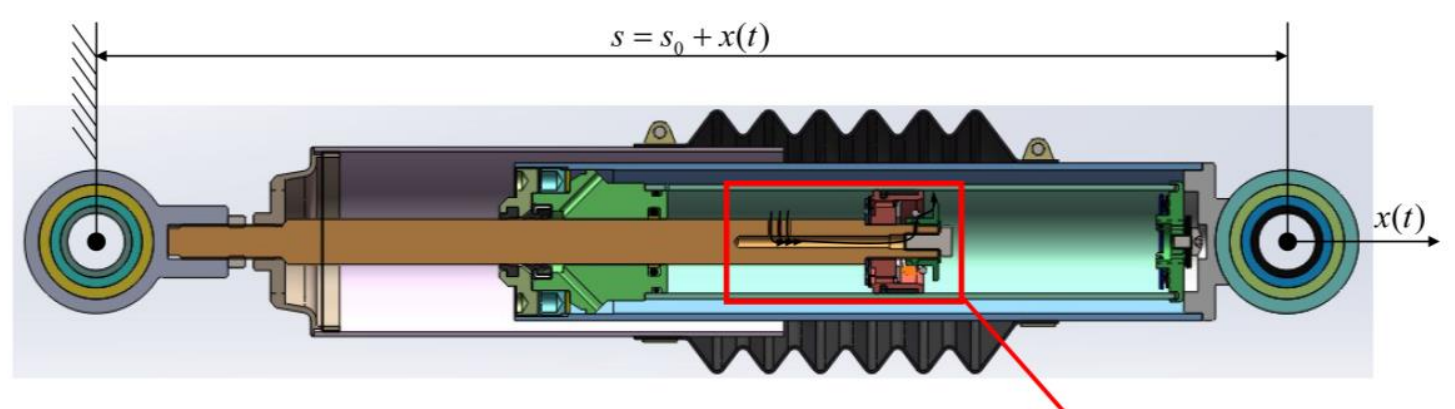

(b)

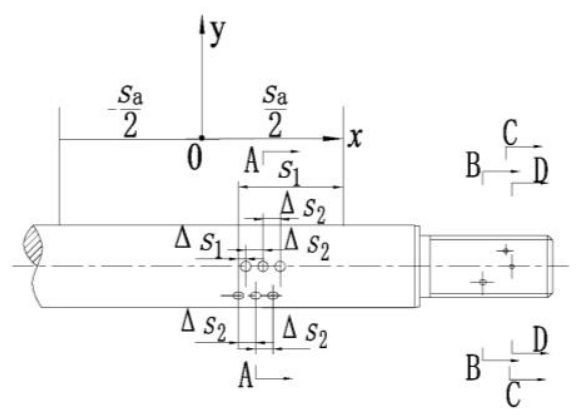

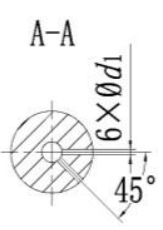

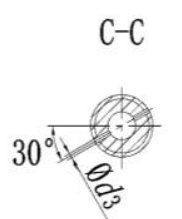

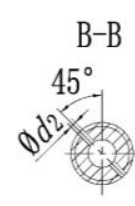

D-D

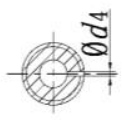

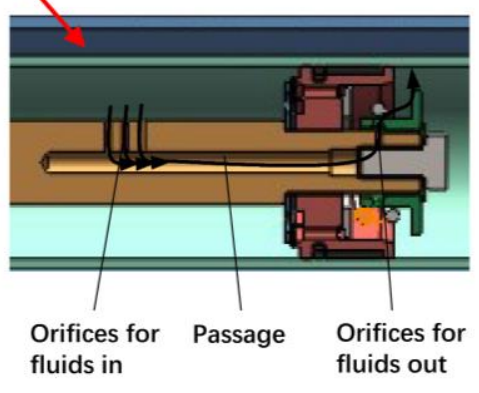

fluids in

Fig. 4 (a) Cross-section of the pantograph damper; (b) engineering drawing of the cross-sections and dimensions of the orifices in the rod

A full parametric model of the pantograph damper has been built in the literature [26]; however, in the pantograph dynamics simulation, a simplified parametric model is wieldier and more efficient.

\subsubsection{Damping performance in the extension stroke}


During the extension stroke of the damper, referring to Fig. 4, it is easy to write the following fluid continuity equations

$$
\begin{aligned}
& Q_{\mathrm{work}}=A_{\mathrm{x}} \dot{x}(t)=C_{\mathrm{d} 1} A_{n}\left[\frac{2}{\rho}\left(P-P_{\mathrm{i}}\right)\right]^{1 / 2} \\
& Q_{\text {work }}=C_{\mathrm{d} 1} A_{\mathrm{f}}\left(\frac{2}{\rho} P_{\mathrm{i}}\right)^{1 / 2}
\end{aligned}
$$

where the pressure action area $A_{\mathrm{x}}$ of the piston during the extension stroke of the damper and the constant cross-section area $A_{\mathrm{f}}$ of the orifices in the rod for fluids outflow are written as

$$
A_{\mathrm{x}}=\frac{\pi}{4}\left(D^{2}-d^{2}\right), A_{\mathrm{f}}=\frac{\pi}{4}\left(2 d_{2}^{2}+2 d_{3}^{2}+d_{4}^{2}\right)
$$

The changeable cross-section area $A_{n}$ of the orifices in the rod for fluids inflow is described by

$$
A_{n}=\frac{\pi}{4}\left(d_{0}^{2}+n d_{1}^{2}\right), n=0,1, \cdots 6
$$

We combine Eqs. (24) and (25) to obtain

$$
P=\frac{\rho A_{\mathrm{x}}{ }^{2}\left(A_{\mathrm{f}}{ }^{2}+A_{n}{ }^{2}\right)}{2 C_{\mathrm{d} 1}{ }^{2} A_{\mathrm{f}}{ }^{2} A_{n}{ }^{2}} \dot{x}^{2}(t)
$$

Thus, the damping force during the extension stroke of the damper is

$$
F_{\mathrm{d}}=P A_{\mathrm{x}}=\frac{\rho A_{\mathrm{x}}^{3}\left(A_{\mathrm{f}}{ }^{2}+A_{n}^{2}\right)}{2 C_{\mathrm{d} 1}{ }^{2} A_{\mathrm{f}}{ }^{2} A_{n}{ }^{2}} \dot{x}^{2}(t)
$$

if defining a constant

$$
k_{11}=\frac{\rho A_{\mathrm{x}}^{3}}{2 C_{\mathrm{d} 1}{ }^{2} A_{\mathrm{f}}^{2}}
$$

it is easy to obtain

$$
F_{\mathrm{d}}=k_{11}\left(1+\frac{A_{\mathrm{f}}^{2}}{A_{n}^{2}}\right) \dot{x}^{2}(t)
$$

Therefore, the damping coefficient of the pantograph damper during extension can be written as

$$
C_{\mathrm{ext}}=k_{11}\left(1+\frac{A_{\mathrm{f}}^{2}}{A_{n}^{2}}\right) \dot{x}(t)
$$

Eq. (32) indicates that the damping coefficient of the damper during extension is governed by its displacement in relation to parameter $A_{n}$, and its speed $\dot{x}(t)$.

\subsubsection{Damping performance in the compression stroke}

During the compression stroke of the damper, referring to Fig. 4, it is also easy to write the following 
fluid continuity equation

$$
Q_{\text {work }}=A_{\mathrm{c}} \dot{x}(t)=C_{\mathrm{d} 1}\left(\frac{\pi}{4} d_{0}^{2}\right)\left(\frac{2}{\rho} P\right)^{1 / 2}+C_{\mathrm{d} 2}\left[\left.2 \pi r_{\mathrm{s}} C_{\mathrm{e}} C_{\mathrm{w}}\right|_{r=r_{\mathrm{s}}} \frac{P}{E\left(h_{1}^{3}+h_{2}^{3}+\cdots+h_{\mathrm{n}}^{3}\right)}\right]\left(\frac{2}{\rho} P\right)^{1 / 2}
$$

where the pressure action area $A_{\mathrm{c}}$ of the piston during the compression stroke of the damper is written as

$$
A_{\mathrm{c}}=\frac{\pi}{4} d^{2}
$$

the amount of fluid that passes through the small constant orifice $d_{0}$ in the inner tube is very small and on a different scale, when compared with the amount of fluid that passes through the compression shim-stack valve in the foot valve assembly. Thus, if we neglect the flow relating to constant orifice $d_{0}$ in Eq. (33) and define a constant for the shim-stack valve

$$
k_{12}=\frac{\left.2 \pi C_{\mathrm{d} 2} r_{\mathrm{s}} C_{\mathrm{e}} C_{\mathrm{w}}\right|_{r=r_{\mathrm{s}}}}{E\left(h_{1}^{3}+h_{2}^{3}+\cdots+h_{n}^{3}\right)} \sqrt{\frac{2}{\rho}}
$$

it is easy to solve Eq. (33) and obtain

$$
P=\left(\frac{A_{\mathrm{c}}}{k_{12}}\right)^{\frac{2}{3}}[\dot{x}(t)]^{\frac{2}{3}}
$$

Hence, the damping force during the compression stroke of the damper is

$$
F_{\mathrm{d}}=P A_{\mathrm{c}}=A_{\mathrm{c}}\left(\frac{A_{\mathrm{c}}}{k_{12}}\right)^{\frac{2}{3}}[\dot{x}(t)]^{\frac{2}{3}}
$$

We continue to define a constant

$$
k_{13}=A_{c}\left(\frac{A_{c}}{k_{12}}\right)^{\frac{2}{3}}
$$

to obtain

$$
F_{\mathrm{d}}=k_{13}[\dot{x}(t)]^{\frac{2}{3}}
$$

Thus, the damping coefficient of the pantograph damper during compression can be written as

$$
C_{\text {com }}=k_{13}[\dot{x}(t)]^{-\frac{1}{3}}
$$

\subsubsection{Simplified-parametric pantograph damper model}

In engineering, it is feasible to assume that the pantograph is lowered with a constant speed before the orifices in the rod begin to be sequentially shielded by the guide seat. Thus, referring to Eq. (32), $C_{\mathrm{ext}}$ can be considered a constant in this process and defined as $C_{0}$.

However, when the orifices in the rod begin to be sequentially shielded, the damping coefficient 
becomes large and complex; Eqs. (31) and (32) are available to describe the notably nonlinear behaviour in this process.

Similarly, we can assume that the pantograph is raised with a constant speed, and the speed is mainly determined by the performance of the pneumatic actuator. In addition, Eq. (39) indicates that the speed $\dot{x}(t)$ weakly affects the damping force, so $F_{\mathrm{d}}$ can be considered a constant. In fact, the compression shim-stack valve in the foot valve assembly is similar to a relief valve; when the damper is compressed, the damping forces are approximately constant and defined as $F_{\text {const. }}$

Therefore, a simplified-parametric pantograph damper model is proposed as follows

$$
F_{\mathrm{d}}=\left\{\begin{array}{l}
C_{0} \dot{x}(t), \text { if } \dot{x}(t) \geq 0,-\frac{s_{\mathrm{a}}}{2} \leq x(t)<\left(\frac{s_{\mathrm{a}}}{2}-s_{1}\right), \\
k_{11}\left(1+\frac{A_{\mathrm{f}}^{2}}{A_{n}^{2}}\right)[\dot{x}(t)]^{2}, n=0,1, \ldots, n-1, \text { if } \dot{x}(t) \geq 0,\left(\frac{s_{\mathrm{a}}}{2}-s_{1}\right) \leq x(t) \leq \frac{s_{\mathrm{a}}}{2}, \\
F_{\text {const }}, \text { if } \dot{x}(t)<0 .
\end{array}\right.
$$

Equation (41) is a concise model with apparent physical meaning to describe the nonlinear displacement-dependent damping characteristics of the pantograph damper. For a given type of pantograph damper, the second item in Eq. (41) can be subdivided according to the concrete configuration of the orifice network. For example, for the damper structure in Fig. 4, Eq. (41) can be concretely written as

$$
F_{\mathrm{d}}= \begin{cases}C_{0} \dot{x}(t), & \text { if } \dot{x}(t) \geq 0,-\frac{s_{\mathrm{a}}}{2} \leq x(t)<\left(\frac{s_{\mathrm{a}}}{2}-s_{1}\right), \\ k_{11}\left(1+\frac{A_{\mathrm{f}}^{2}}{A_{5}^{2}}\right)[\dot{x}(t)]^{2}, & \text { if } \dot{x}(t) \geq 0,\left(\frac{s_{\mathrm{a}}}{2}-s_{1}\right) \leq x(t)<\left[\left(\frac{s_{\mathrm{a}}}{2}-s_{1}\right)+\Delta s_{1}\right], \\ k_{11}\left(1+\frac{A_{\mathrm{f}}^{2}}{A_{4}^{2}}\right)[\dot{x}(t)]^{2}, \text { if } \dot{x}(t) \geq 0, & {\left[\left(\frac{s_{\mathrm{a}}}{2}-s_{1}\right)+\Delta s_{1}\right] \leq x(t)<\left[\left(\frac{s_{\mathrm{a}}}{2}-s_{1}\right)+\Delta s_{2}\right],} \\ k_{31}{ }^{2} & \left(1+\frac{A_{\mathrm{f}}^{2}}{A_{2}^{2}}\right)[\dot{x}(t)]^{2}, \text { if } \dot{x}(t) \geq 0,\left[\left(\frac{s_{\mathrm{a}}}{2}-s_{1}\right)+\Delta s_{2}\right] \leq x(t)<\left[\left(\frac{s_{\mathrm{a}}}{2}-s_{1}\right)+\Delta s_{1}+\Delta s_{2}\right], \\ k_{11}\left(1+\frac{A_{\mathrm{f}}^{2}}{A_{1}^{2}}\right)[\dot{x}(t)]^{2}, & \text { if } \dot{x}(t) \geq 0,\left[\left(\frac{s_{\mathrm{a}}}{2}-s_{1}\right)+2 \Delta s_{2}\right] \leq x(t)<\left[\left(\frac{s_{\mathrm{a}}}{2}-s_{1}\right)+\Delta s_{1}+2 \Delta s_{2}\right], \\ k_{11}\left(1+\frac{A_{\mathrm{f}}^{2}}{A_{0}^{2}}\right)[\dot{x}(t)]^{2}, & \text { if } \dot{x}(t) \geq 0,\left[\left(\frac{s_{\mathrm{a}}}{2}-s_{1}\right)+\Delta s_{1}+2 \Delta s_{2}\right] \leq x(t) \leq \frac{s_{\mathrm{a}}}{2}, \\ F_{\text {const }}, & \text { if } \dot{x}(t)<0 .\end{cases}
$$


where $A_{0}-A_{5}$ can be calculated using Eq. (27). In addition, according to Fig. 4, we have $s=s_{0}+x(t), \dot{s}=\dot{x}(t)$

Thus, the above simplified-parametric damper model can be easily coupled with the pantograph dynamics model and used for pantograph dynamics simulations.

\subsubsection{Damper model validation}

Both computer simulation and experimental research (Fig. 5) were performed to verify the proposed simplified-parametric pantograph damper model, and the results are shown in Fig. 6.

Fig. 6 compares the tested nominal-speed force vs. displacement $\left(\boldsymbol{F}_{\mathrm{d}-\boldsymbol{x}} \boldsymbol{x}(\boldsymbol{t})\right)$ characteristics with the simulated $\boldsymbol{F}_{\mathrm{d}} \boldsymbol{x}(\boldsymbol{t})$ characteristics of a high-speed rail pantograph hydraulic damper (Type: J6H36-02-00). Fig. 6 demonstrates that the test result is consistent with the simulation result, except for small biases in lower-level damping forces, and the biases are notably small and tolerable. In addition, the tested damping force sometimes appears less stable than the simulated damping force, which is common in practical product tests.

In section "a-b", the pantograph begins to be lowered, so the damper begins to extend. Because all

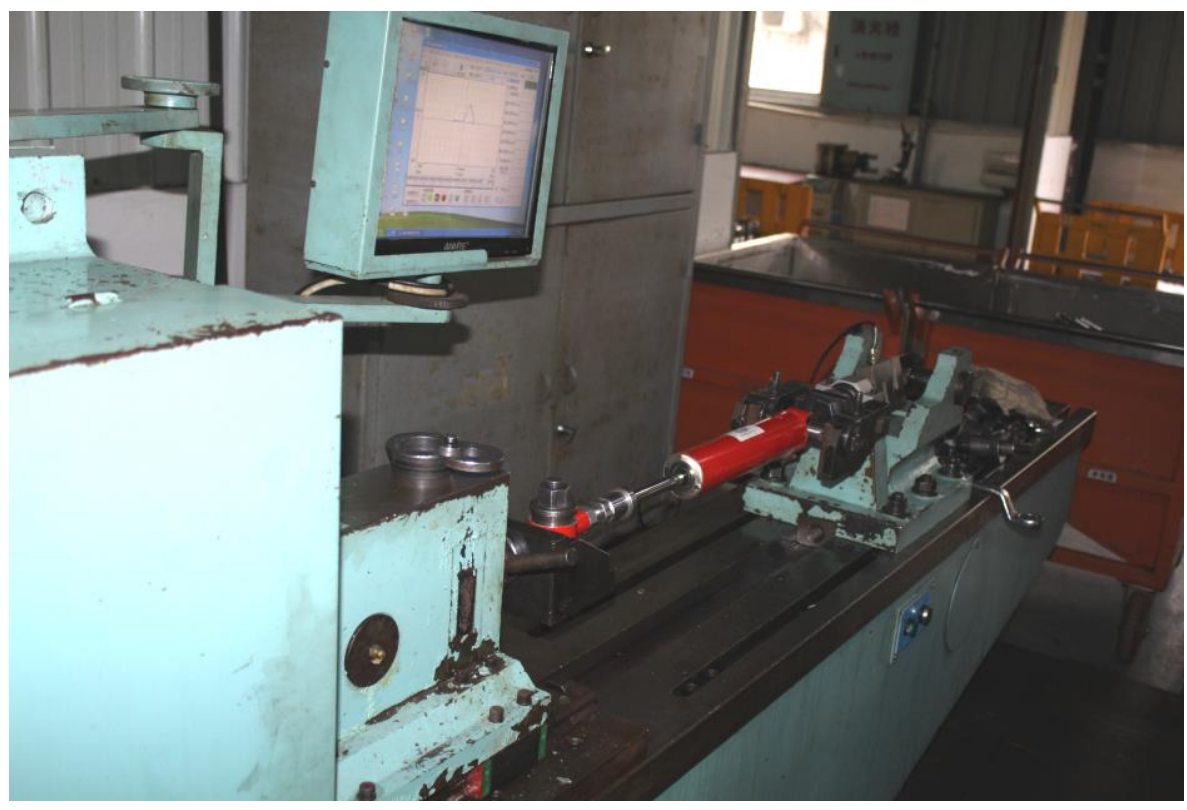

Fig. 5 Bench testing of a high-speed rail pantograph hydraulic damper 


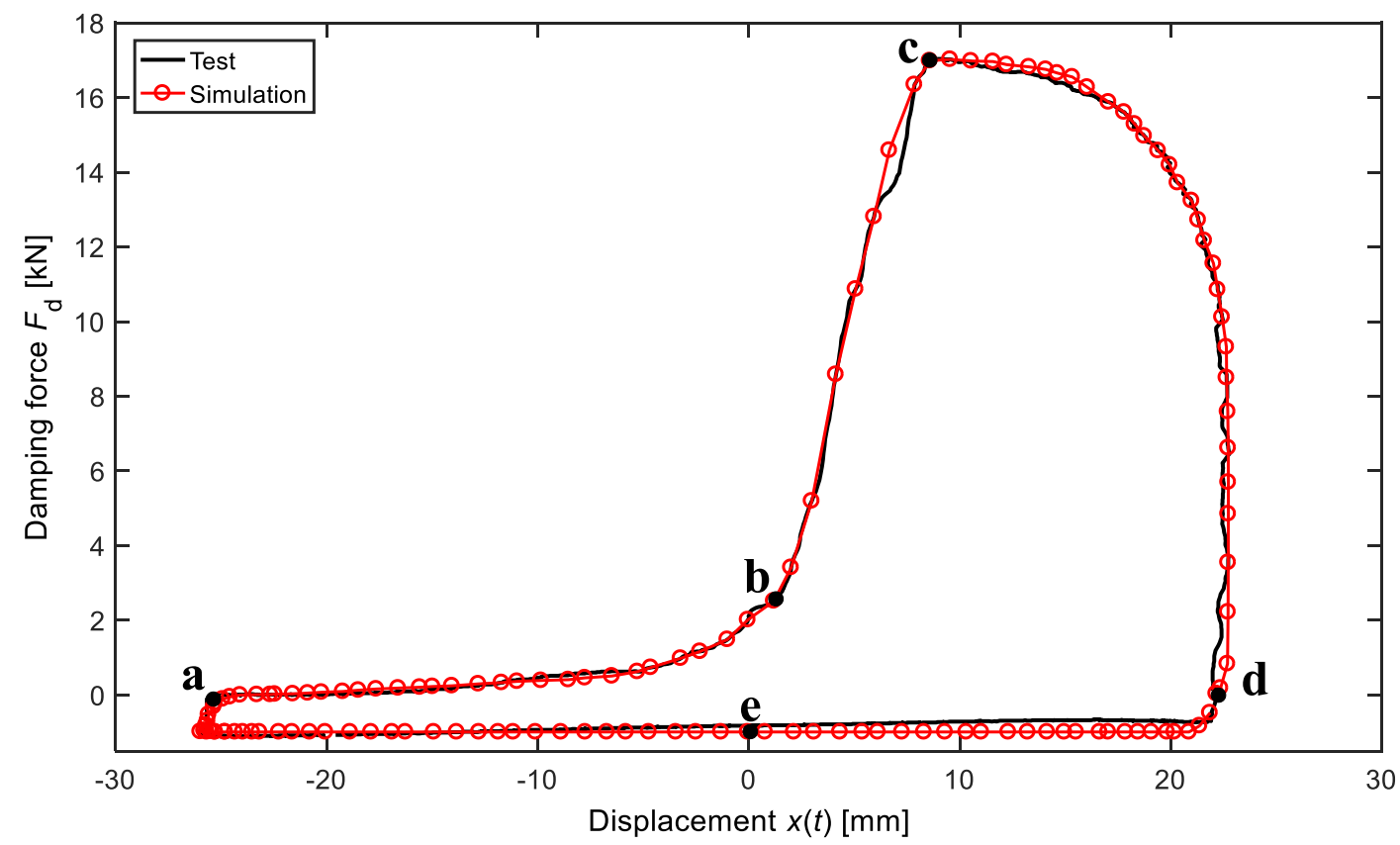

Fig. 6 Nominal-speed force vs. displacement $\left(\boldsymbol{F}_{\mathrm{d}}-\boldsymbol{x}(\boldsymbol{t})\right)$ characteristics of a high-speed rail pantograph hydraulic damper (Type: $\mathrm{J} 6 \mathrm{H} 36-02-00$ ) with a harmonic excitation of displacement amplitude of $\pm 24.38 \mathrm{~mm}$, a frequency of $0.65 \mathrm{~Hz}$ and a velocity amplitude of $\pm 0.1 \mathrm{~m} / \mathrm{s}$

orifices in the rod are available to charge the fluids, the damping force slowly increases although the excitation speed improves, so this is good for fast descending of the pantograph.

However, in section "b-c", the orifices in the rod begin to be sequentially shielded, so the damping forces drastically increase, and the descending speed of the pantograph quickly decreases. In section "c-d", although only the constant orifice in the inner tube works, the pantograph speed is approaching zero, so the damping force quickly descends to zero, and the pantograph is stopped and rests on the compartment roof.

In section "d-e-a", the pantograph is raised, so the damper is compressed. Because the compression shim-stack valve in the foot valve assembly plays a dominate role and acts as a relief valve in this process, the damper supplies a low-level and approximately constant damping force to the pantograph.

Thus, the proposed simplified-parametric model is validated by experimental results; the concise model accurately captures the nonlinear displacement-dependent damping characteristics of the pantograph hydraulic damper, and it appears more complete and accurate. 


\section{Effect of the damper characteristics on the pantograph dynamics}

A detailed MATALB/Simulink model was developed using the deduced full mathematical model of the pantograph-catenary system in Section 2, with which the proposed simplified-parametric pantograph damper model was coupled. The parameter values in the MATALB/Simulink model for the dynamics simulation are summarized in the Appendix.

In the simulation, three cases of damper characteristics were used. Case 1 has high-level damping characteristics with $C_{0}=15.57 \mathrm{kN} \mathrm{s} / \mathrm{m}$, maximum damping performance at section "b-c-d", which can be calculated by the second item in Eq. (41), and $F_{\text {const }}=927.7$ N. Case 2 has medium-level damping characteristics with $C_{0}=9.50 \mathrm{kN} \mathrm{s} / \mathrm{m}$, medium damping performance at section "b-c-d", and $F_{\text {const }}=480 \mathrm{~N}$. Case 3 has low-level damping characteristics with $C_{0}=4.00 \mathrm{kN} \mathrm{s} / \mathrm{m}$, minimum damping performance at section "b-c-d", and $F_{\text {const }}=31 \mathrm{~N}$.

\subsection{Raising performance}

When the pantograph is raised (the vehicle is stationary), the damper is compressed and works in section "d-e-a" as shown in Fig. 6, the $F_{\text {const }}$ in Eq. (41) represents the level of damping in section "d-e-a".

Fig. 7 demonstrates the instantaneous current collector height and contact force of the pantograph when it is raised. Fig. 7 (a) shows that the pantograph with a small $F_{\text {const }}$ (Case 3 ) is quickly raised, but the collector fluctuates with large amplitudes, and for a long time after its first impact with the catenary, the contact (impact) forces during fluctuation are large, as shown in Fig. 7(b). The pantograph with a high-level $F_{\text {const }}$ (Case 1) is quickly stabilized (Fig. 7(a)), although it is raised for a relatively longer time, and the contact forces are small and quickly stabilized (Fig. 7(b)). The performance of the pantograph with a medium-level $F_{\text {const }}($ Case 2$)$ is between that of Cases 3 and 1.

Fig. 8 summarizes the concrete indices of the pantograph when it is raised and shows that Case 3 has the highest maximum contact force and longest raising time of the pantograph, Case 1 has the lowest maximum contact force and shortest raising time of the pantograph, and the indices in Case 2 are between those of Cases 3 and 1. 
(a)

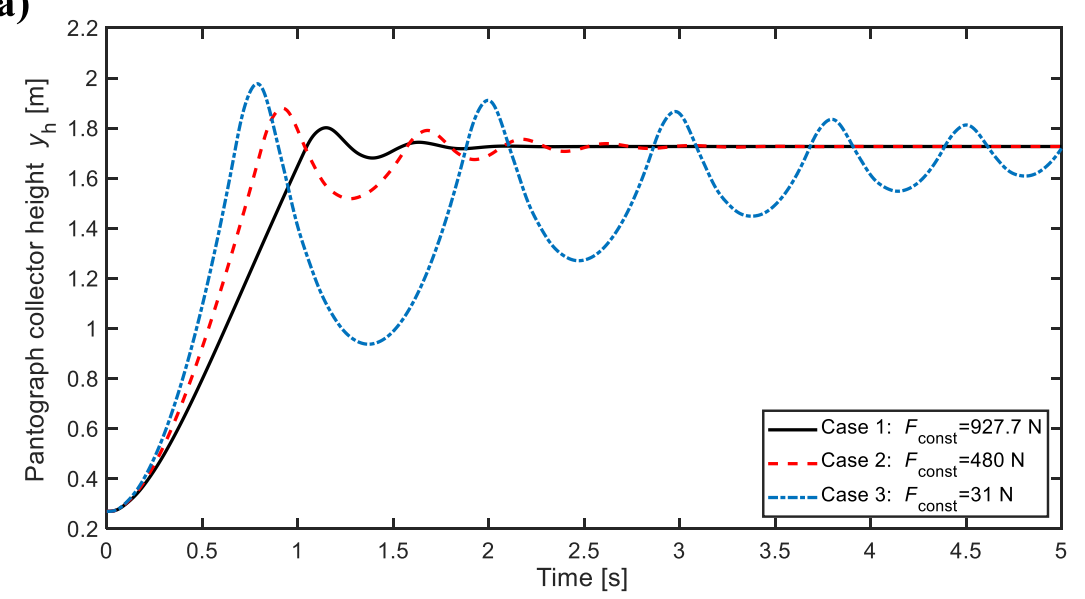

(b)

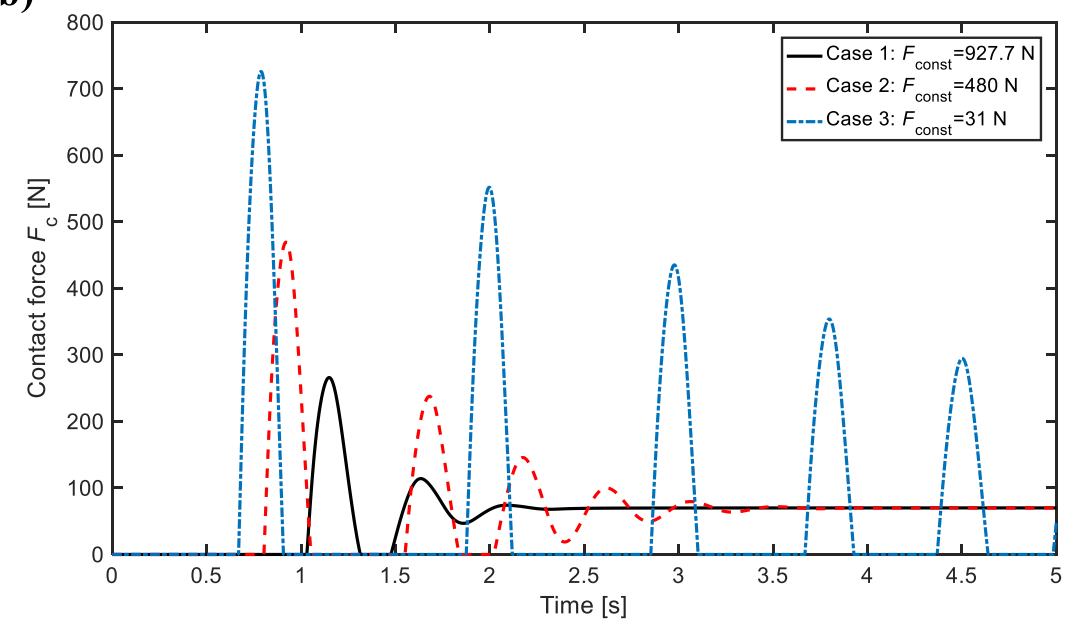

Fig. 7 Instantaneous collector height $y_{\mathrm{h}}(\mathrm{a})$ and contact force $F_{\mathrm{c}}$ (b) during the raising process of the pantograph

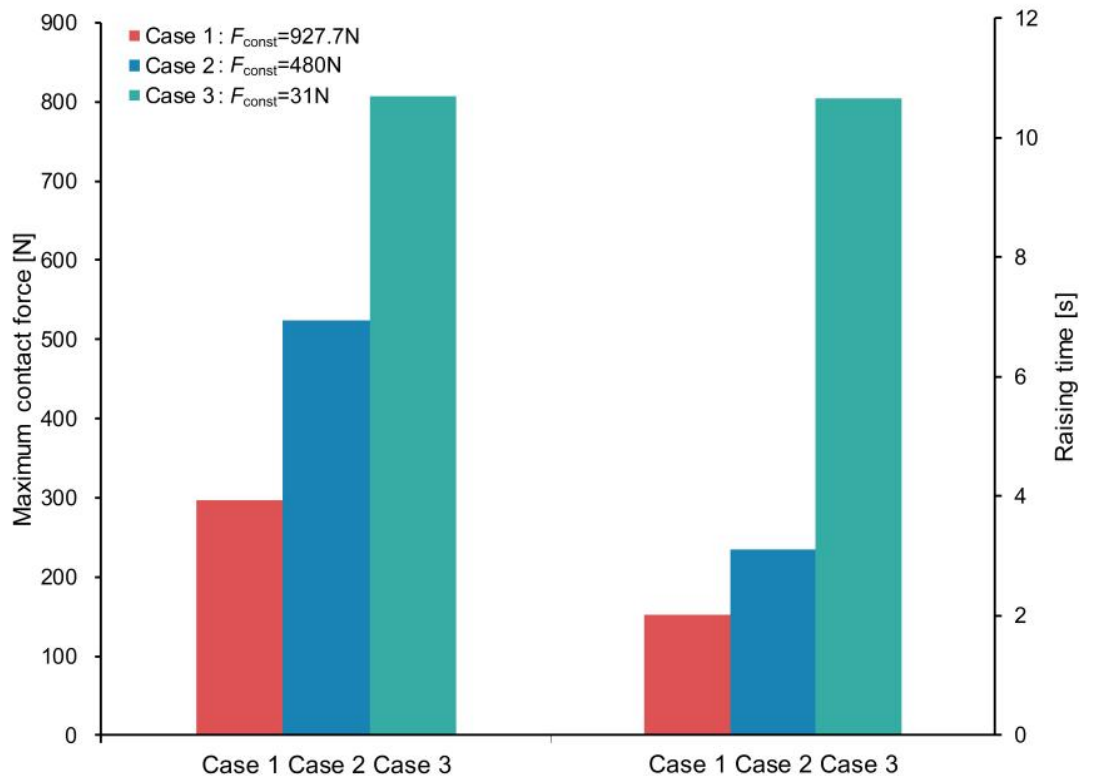

Fig. 8 Maximum contact force and raising time during the raising process of the pantograph 
Thus, from the viewpoint of raising performance, $F_{\text {const }}$ in the pantograph damper model Eq. (41) should not be designed to be too small or zero; otherwise, severe impacts between the pan-head and the catenary and a longer stabilization time of the pantograph will be induced; in other words, $F_{\text {const }}$ has an optimal value.

\subsection{Holding performance}

When the pantograph is operating, i.e., the moving pantograph is holding with the catenary, the pantograph and hydraulic damper experience both high-frequency-low-amplitude vibrations and low-frequency-big-amplitude discrete disturbances. The hydraulic damper works in sections "a-b" and "d-e-a" (Fig. 6) during the holding process, so both parameters $C_{0}$ and $F_{\text {const }}$ in Eq. (41) are crucial to the contact quality of the pan-head and catenary.

\subsubsection{Pulse responses of the pantograph}

The pulse responses of pantograph reflect the stabilization ability of the pantograph against disturbances. When the pantograph is subject to a positive force pulse input, the response of contact force $F_{\mathrm{c}}$ and its Power Spectrum Density (PSD) are demonstrated in Fig. 9. Fig. 9(a) shows that the pantograph with large $C_{0}$ and $F_{\text {const }}($ Case 1$)$ is more easily stabilized in contact force than that with smaller $C_{0}$ and $F_{\text {const }}$ (Cases 2 and 3). Fig. 9(b) also shows that the pantograph with large $C_{0}$ and $F_{\text {const }}$ has weaker energies at the main frequencies of $2.6 \mathrm{~Hz}$ and $5.2 \mathrm{~Hz}$ than the pantograph with smaller $C_{0}$ and $F_{\text {const. }}$.

Fig. 10 demonstrates the displacement pulse response of pantograph collector height $y_{\mathrm{h}}$ and its PSD when the pantograph is holding with the catenary, and indicates that the pantograph with large $C_{0}$ and $F_{\text {const }}$ (Case 1) is more easily stabilized in collector height and has weaker energies at the main frequencies of 1 $\mathrm{Hz}$ and $2.6 \mathrm{~Hz}$ than that with smaller $C_{0}$ and $F_{\text {const }}$ (Cases 2 and 3).

(a)

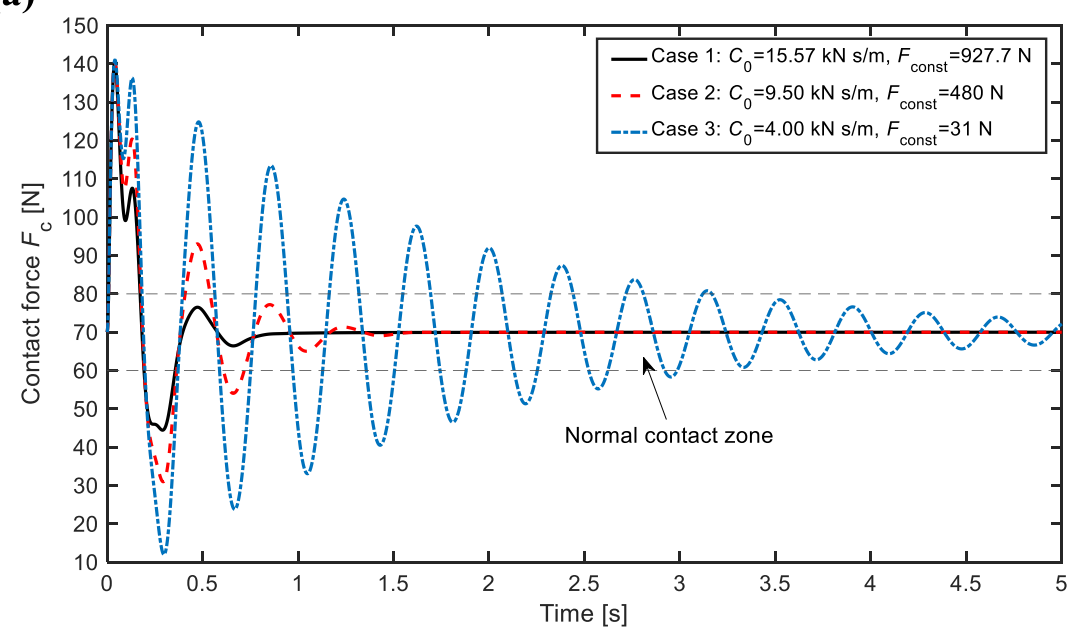


(b)

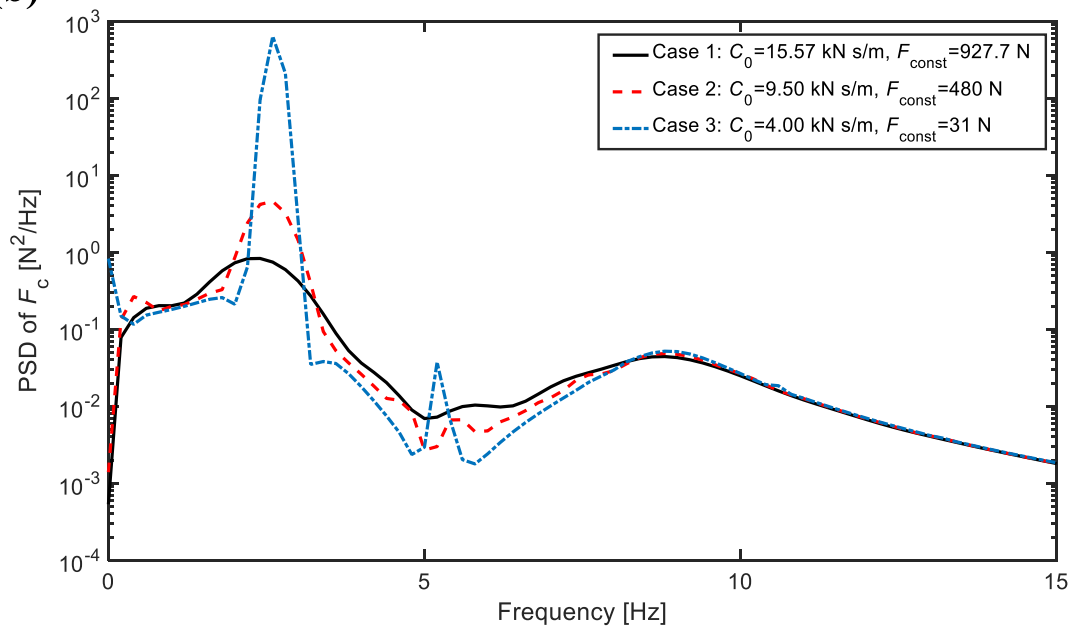

Fig. 9 Force pulse response of contact force $F_{\mathrm{c}}(\mathrm{a})$ and PSD of $F_{\mathrm{c}}(\mathrm{b})$ when the pantograph is holding with the catenary

(a)

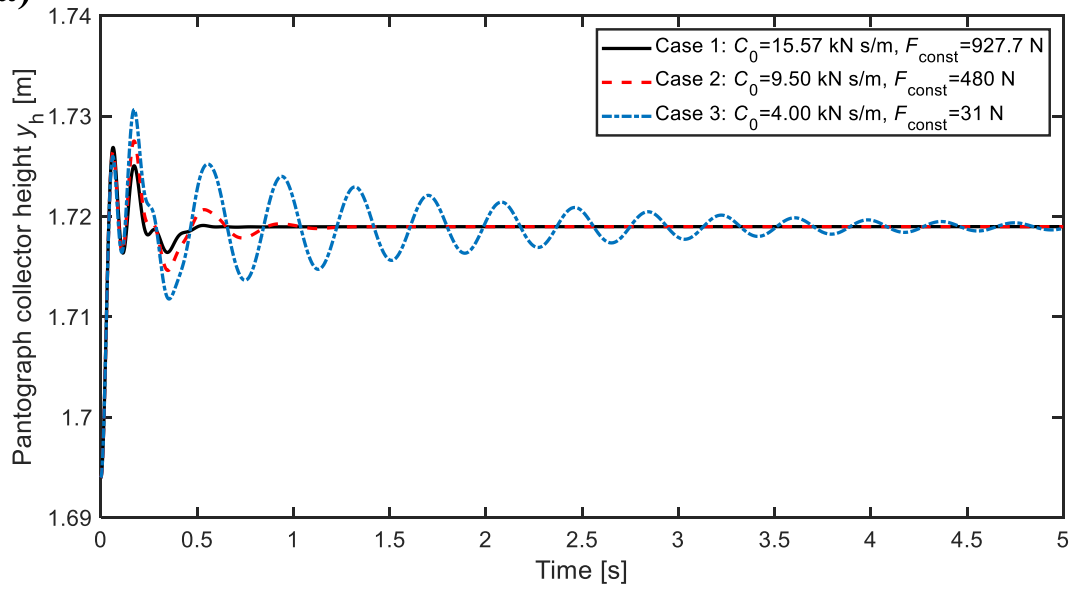

(b)

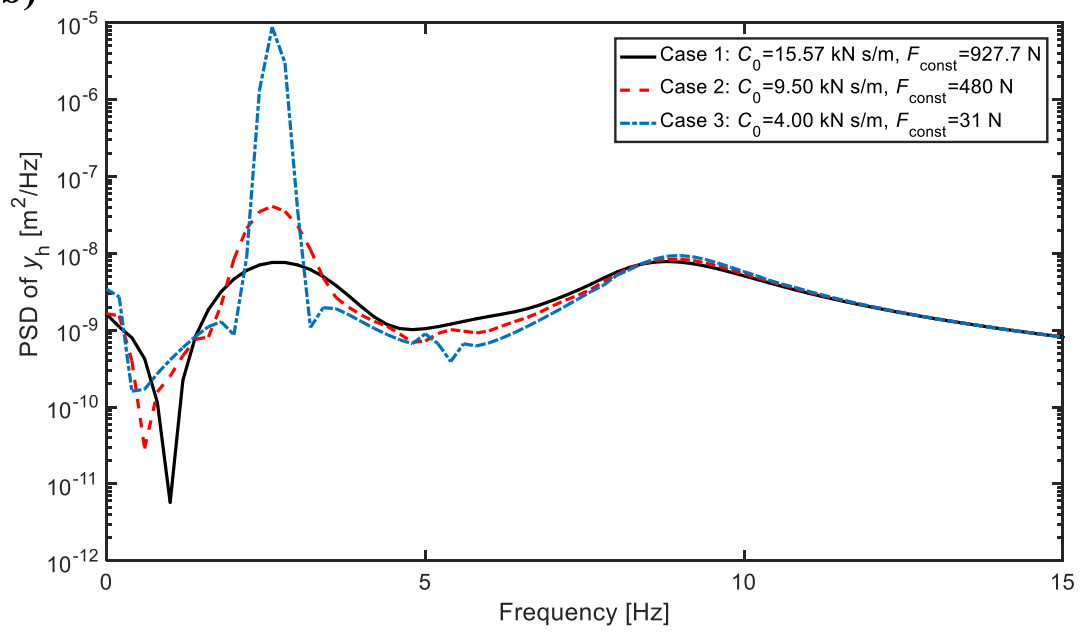

Fig. 10 Displacement pulse response of collector height $y_{\mathrm{h}}$ (a) and PSD of $y_{\mathrm{h}}(\mathrm{b})$ when the pantograph is holding with the catenary 


\subsubsection{Dynamic contact performance of the pantograph and catenary}

Fig. 11 demonstrates the instantaneous current collector height $y_{\mathrm{h}}$ and its PSD when the pantograph moves between the fifth and the seventh spans of the catenary at a speed of $200 \mathrm{~km} / \mathrm{h}$. The pantograph with large $C_{0}$ and $F_{\text {const }}$ (Case 1) has lower vibration amplitudes in collector height (Fig. 11(a)) and weaker energy at the main frequency of $2.6 \mathrm{~Hz}$ (Fig. 11(b)) than that with smaller $C_{0}$ and $F_{\text {const }}$ (Cases 2 and 3). However, the energy intensities at the main frequencies of $0.85 \mathrm{~Hz}$ and $1.77 \mathrm{~Hz}$ do not show remarkable differences among the three cases.

(a)

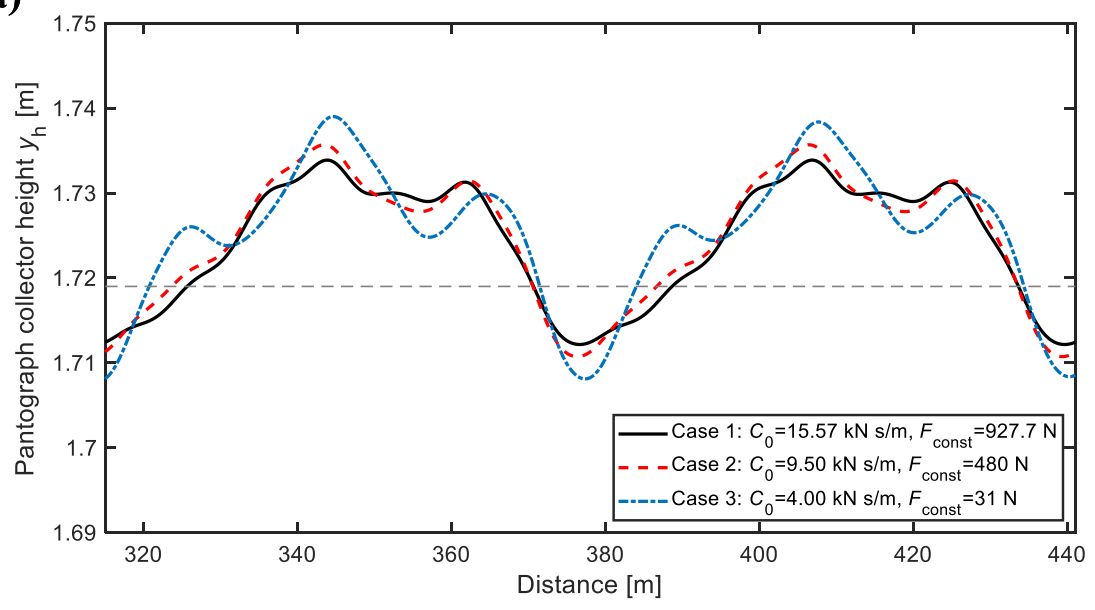

(b)

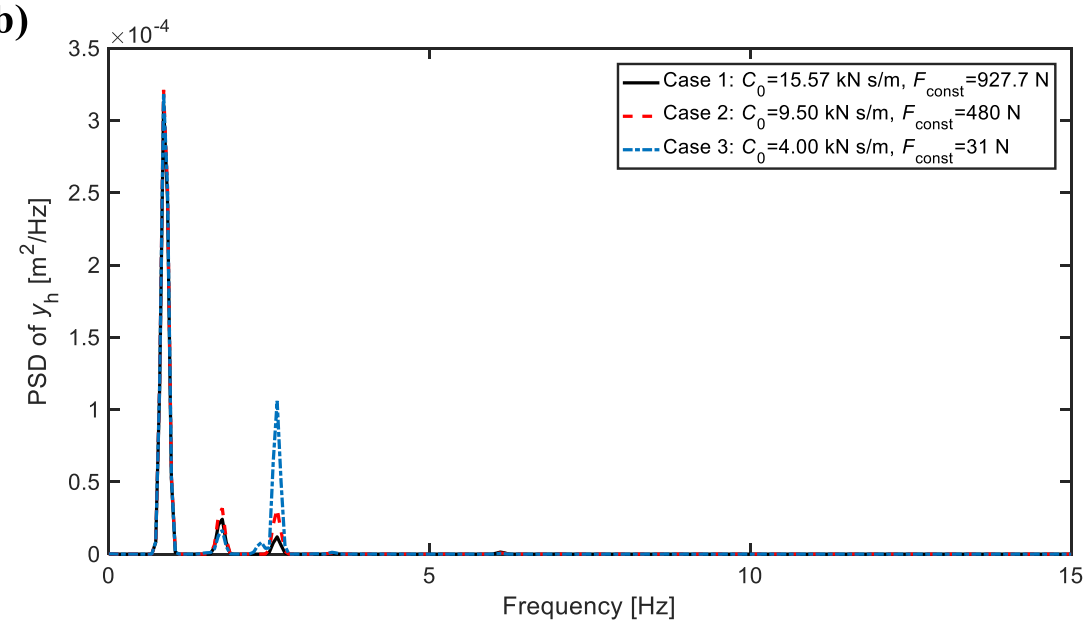

Fig. 11 Instantaneous current collector height $y_{\mathrm{h}}$ (a) and PSD of $y_{\mathrm{h}}(\mathrm{b})$ when pantograph moves between the fifth to the seventh spans of the catenary at a speed of $200 \mathrm{~km} / \mathrm{h}$

Fig. 12 demonstrates the instantaneous contact force $F_{\mathrm{c}}$ and its PSD when the pantograph moves between the fifth and the seventh spans of the catenary at a speed of $200 \mathrm{~km} / \mathrm{h}$. Fig. 12 shows that the pantograph with large $C_{0}$ and $F_{\text {const }}$ (Case 1) has lower-level fluctuating amplitudes in contact force (Fig. 12(a)) and weaker energy at the main frequency of $2.6 \mathrm{~Hz}$ (Fig. 12(b)) than that with smaller $C_{0}$ and $F_{\text {const }}$ (Cases 2 and 3). The differences in energy intensity at other main frequencies are not obvious among the three cases. 
(a)

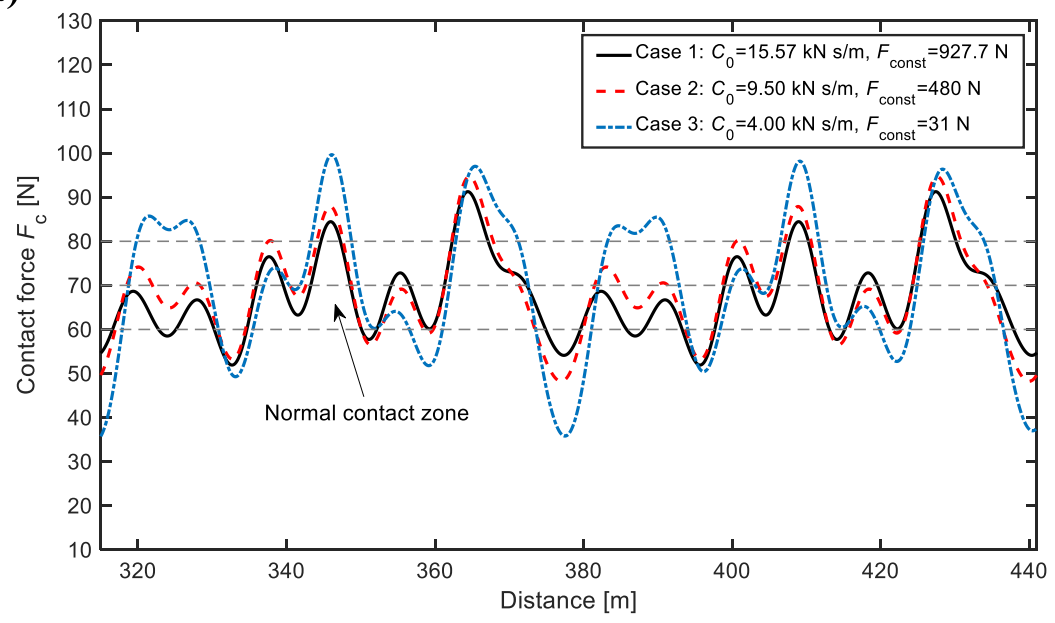

(b)

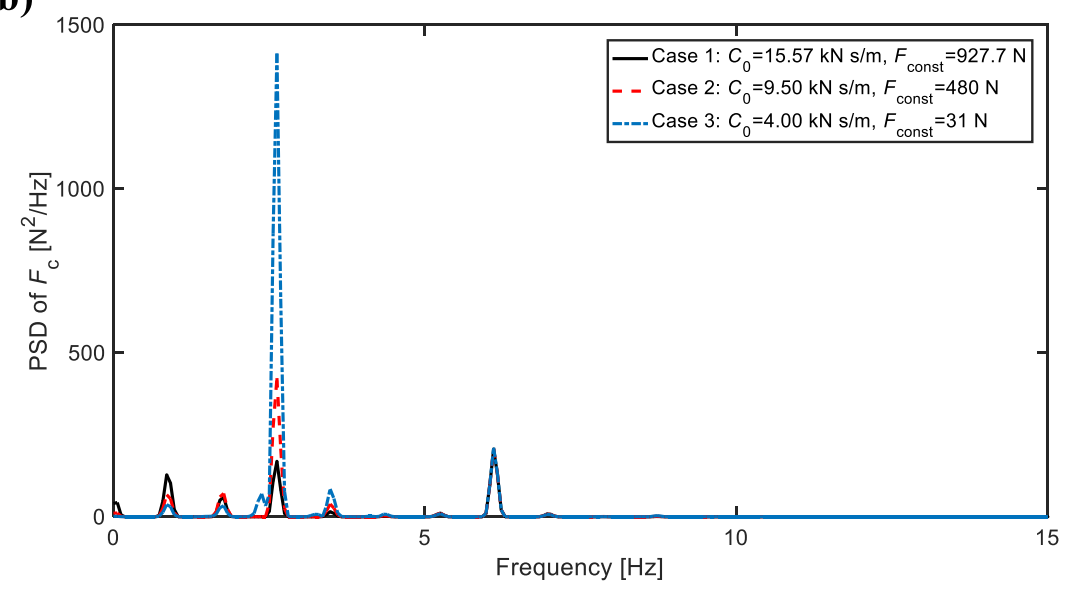

Fig. 12 Instantaneous contact force $F_{\mathrm{c}}$ (a) and PSD of $F_{\mathrm{c}}$ (b) when the pantograph moves between the fifth to the seventh spans of the catenary at a speed of $200 \mathrm{~km} / \mathrm{h}$

(a)

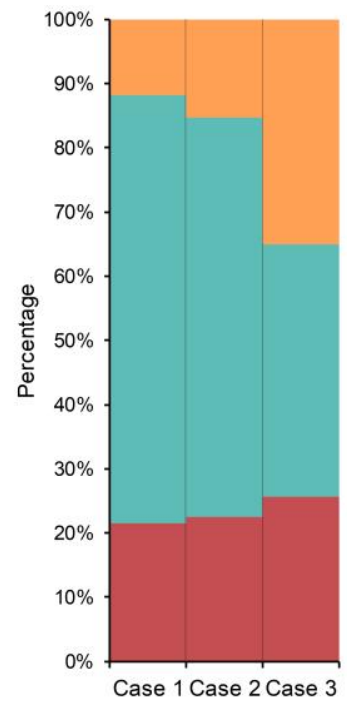

(b)

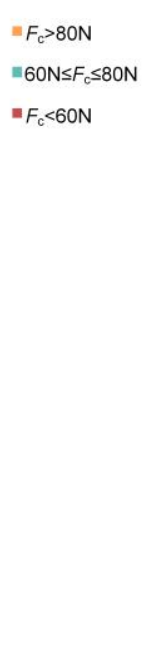

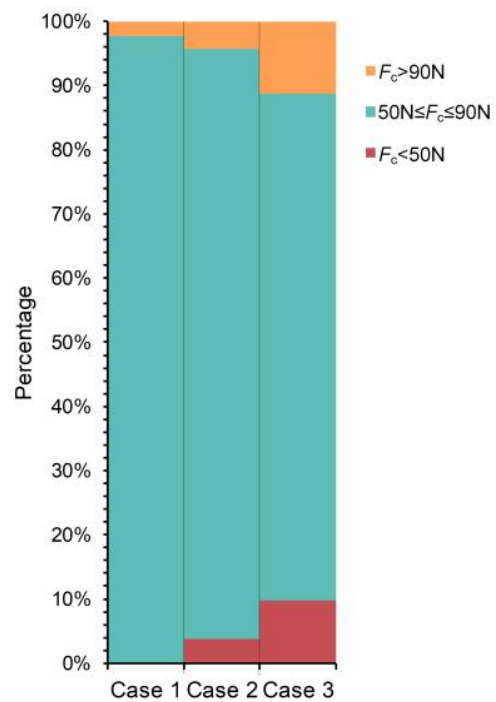

Fig. 13 Normal contact force distributions (a) and extreme contact force distributions (b) of the pantograph 
Fig. 13 summarizes and compares the contact force distributions of the pantograph when the pantograph has different levels of $C_{0}$ and $F_{\text {const. When }} 60 \mathrm{~N} \leq F_{\mathrm{c}} \leq 80 \mathrm{~N}$, the contact force is considered in the normal [27] contact zone, as shown in Figs. 9(a) and 12(a). When $F_{\mathrm{c}}>80 \mathrm{~N}$ or $F_{\mathrm{c}}<60 \mathrm{~N}$, the contact force is considered higher or lower than the normal value. If $F_{\mathrm{c}}>90 \mathrm{~N}$, the contact force is considered too high and may damage the pan-head and catenary; if $F_{\mathrm{c}}<50 \mathrm{~N}$, the contact force is considered too low and the pan-head is about to lose contact with the catenary.

Fig. 13 shows that the percentage of normal contact forces of the pantograph with large $C_{0}$ and $F_{\text {const }}$ (Case 1) is over $66.5 \%$ (Fig. 13(a)) and that of extreme contact forces is below 2.5\% (Fig. 13(b)). However, the percentage of normal contact forces of the pantograph with small $C_{0}$ and $F_{\text {const }}$ (Case 3 ) is only $39.3 \%$ (Fig. 13(a)) and that of extreme contact forces exceeds 21\% (Fig. 13(b)). The percentages of Case 2 are between those of Cases 3 and 1.

Thus, from the viewpoint of contact quality, large $C_{0}$ and $F_{\text {const }}$ in the pantograph damper model (Eq. (41)) can increase the percentage of normal contact forces and reduce that of extreme contact forces. In other words, it can improve the pantograph-catenary contact quality. In engineering, $C_{0}$ and $F_{\text {const }}$ should not be designed to be too small or zero.

\subsection{Lowering performance}

When the pantograph is lowered (the vehicle can be stationary or moving), the damper is stretched and works in section "a-b-c-d" as shown in Fig. 6. If we divide section "a-b-c-d" into "a-b" and "b-c-d", $C_{0}$ represents the damping performance in section "a-b", and the second item in Eq. (41) represents the damping performance in section "b-c-d".

Figs. 14(a) and (b) show the instantaneous height $y_{\mathrm{e}}$ of joint $E$ and velocity $\dot{y}_{\mathrm{e}}$ of joint $E$ when the pantograph is lowered. As an example (Case 1), Fig. 14(b) shows the lowering process of the pantograph; sections "a-b" and "b-c-d" correspond to sections "a-b" and "b-c-d" in Fig. 6, respectively. In section "a-b", the pantograph descends against a relatively small damping of $C_{0}$, so the pantograph speed increases; however, in section "b-c-d", because the pantograph is subject to a very large nonlinear damping, the pantograph speed is drastically reduced in section "b-c" and decreases to zero in section "c-d" when the pantograph impacts the base frame. Fig. 14(b) also illustrates the lowering times $t_{1}$ in section "a-b" and $t_{2}$ in section "b-c-d"; the sum of $t_{1}$ and $t_{2}$ is equal to the total lowering time of the pantograph.

Fig. 14(b) indicates that speed of the pantograph with high-level damping (Case 1) is quickly reduced but requires a longer time to reach zero, whereas the speed of the pantograph with low-level damping (Case 3 ) is slowly reduced but quickly reaches zero. However, because of the considerable impact of the pantograph and base frame in Case 3, the final speeds drastically fluctuate. The final impact intensity is also observed in Fig. 14(c), where the pantograph with low-level damping (Case 3) has the largest velocity 
(a)

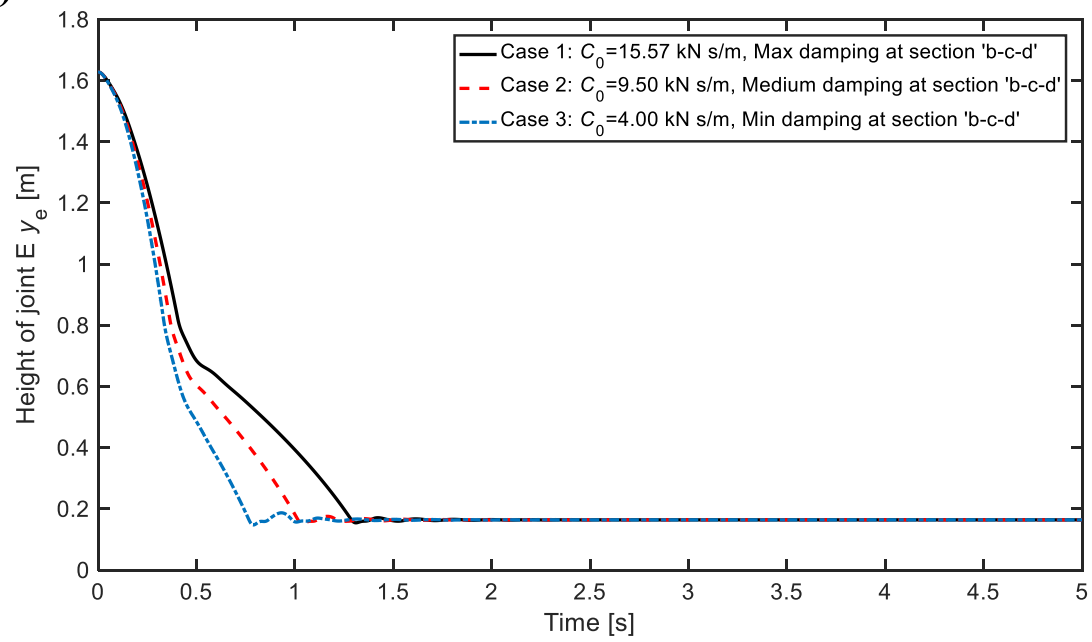

(b)

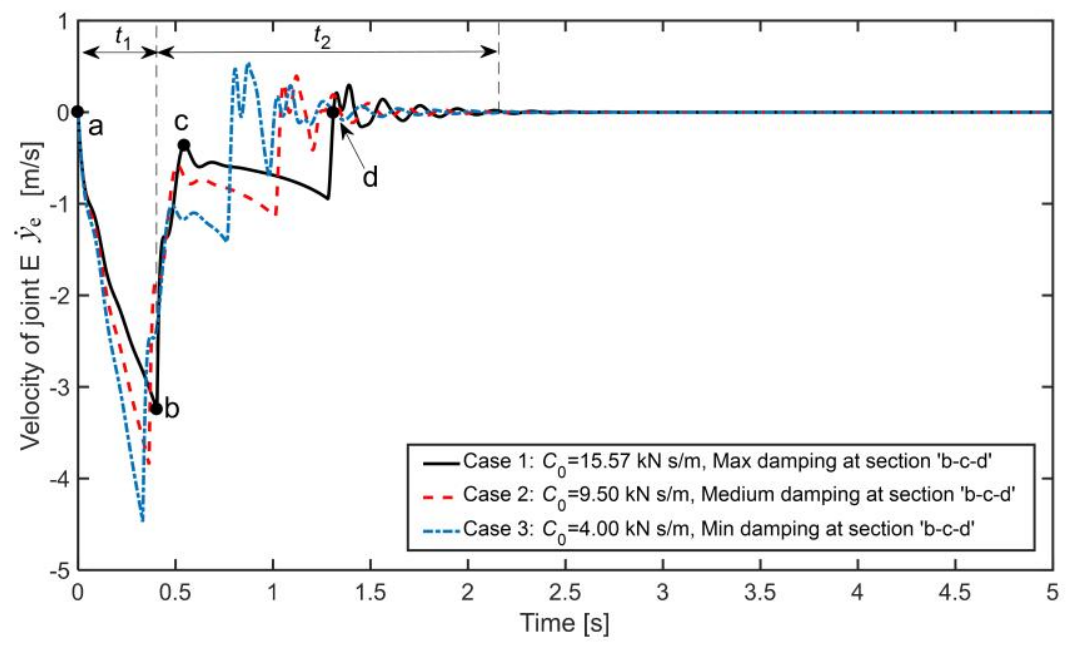

(c)

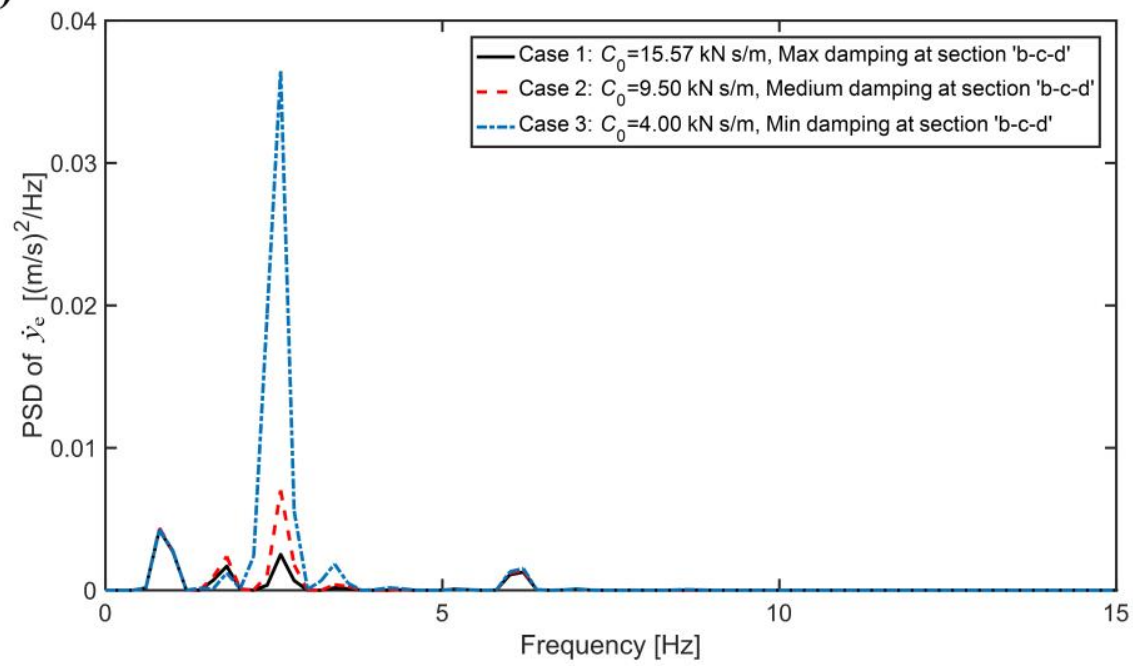

Fig. 14 Instantaneous height $y_{\mathrm{e}}(\mathrm{a})$ and velocity $\dot{y}_{\mathrm{e}}(\mathrm{b})$ of joint $E$ and PSD of $\dot{y}_{\mathrm{e}}(\mathrm{c})$ when the pantograph is lowered impact energy at the main frequency of $2.6 \mathrm{~Hz}$. 
Fig. 15 demonstrates the instantaneous acceleration $\ddot{y}_{\mathrm{e}}$ of joint $E$ and PSD of $\ddot{y}_{\mathrm{e}}$ when the pantograph is lowered. Fig. 15(a) shows that the pantograph with a high-level damping (Case 1) has the largest maximum acceleration in the speed reduction process, i.e., section "b-c" of Fig. 14(b), and the smallest maximum impact acceleration in the final process, i.e., section "c-d" of Fig. 14(b). Fig. 15(a) also shows that the pantograph with low-level damping (Case 3) has the largest maximum impact acceleration in the final process. In the frequency domain, Fig. 15(b) obviously shows that the pantograph in Case 3 has the largest acceleration impact energies at the main frequencies of $9.2 \mathrm{~Hz}$ and $13.8 \mathrm{~Hz}$.

(a)

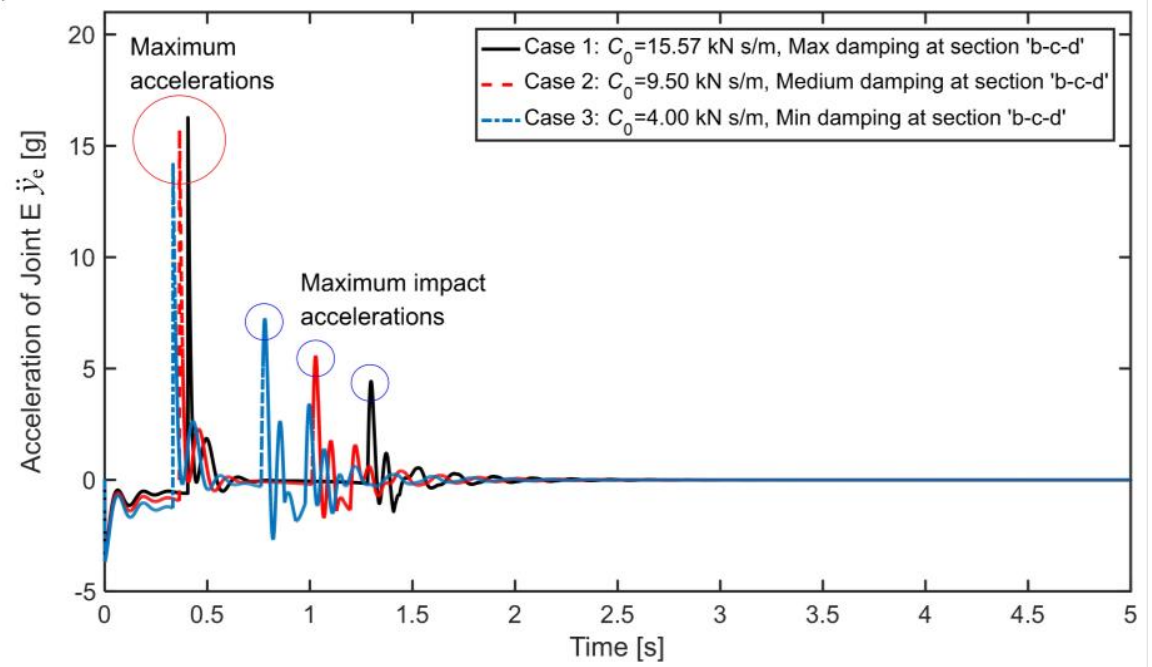

(b)

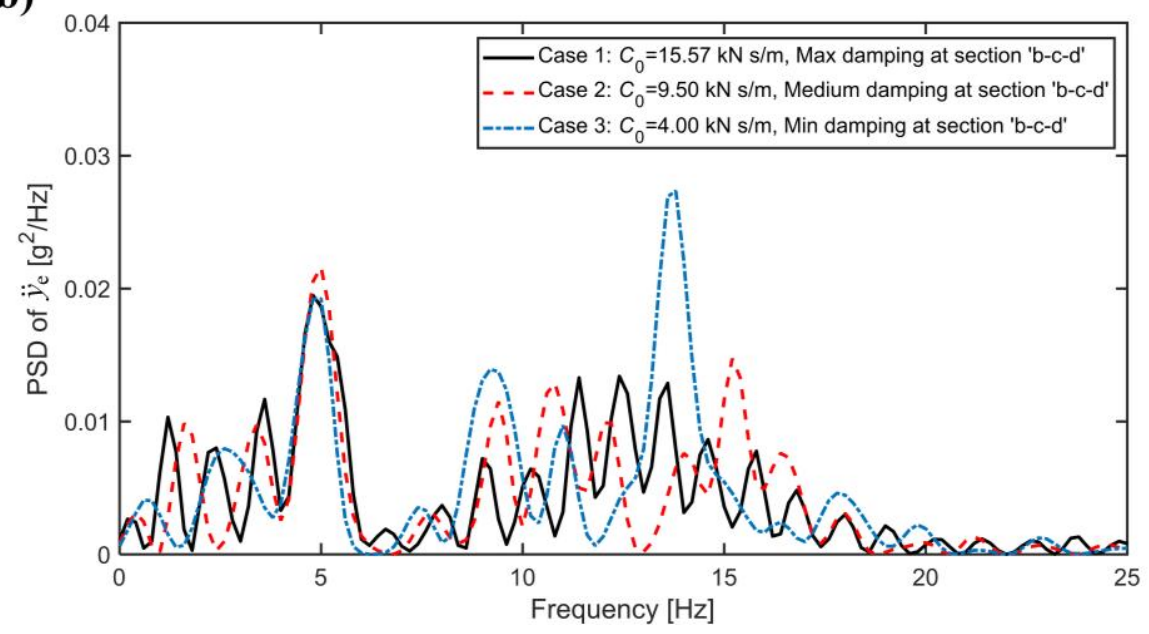

Fig. 15 Instantaneous acceleration $\ddot{y}_{\mathrm{e}}$ of joint $E$ (a) and PSD of $\ddot{y}_{\mathrm{e}}(\mathrm{b})$ when the pantograph is lowered

Fig. 16 demonstrates the instantaneous vertical momentum and PSD of the vertical momentum of the pantograph when the pantograph is lowered. In the main section of speed reduction "b-c", the pantograph with a high-level damping (Case 1) has the largest vertical momentum (Fig. 16(a)) and vertical momentum energies (Fig. 16(b)) at the main frequencies of $0.2 \mathrm{~Hz}$ and $1.2 \mathrm{~Hz}$. However, in the final impact process, the pantograph with low-level damping (Case 3) has the largest vertical momentum (Fig. 16(a)) and vertical 
momentum energies (Fig. 16(b)) at the main frequency of $4.2 \mathrm{~Hz}$.

Fig. 17 summarizes the lowering time in terms of $t_{1}$ and $t_{2}$, maximum acceleration and maximum impact acceleration of the pantograph during the lowering process. Fig. 17(a) indicates that the differences in lowering time $t_{1}$ in the first stage "a-b" are not obvious among the three cases, so the damping coefficient $C_{0}$ has no obvious effect on the lowering time of the pantograph. Fig. 17(a) also indicates that the higher level of damping in section "b-c-d" of the damper corresponds to a longer total lowering time of the pantograph. In other words, the damping performance in section "b-c-d" (Fig. 6 and the second item in Eq. (41)) of the damper has an obvious effect on the lowering time of the pantograph.

(a)

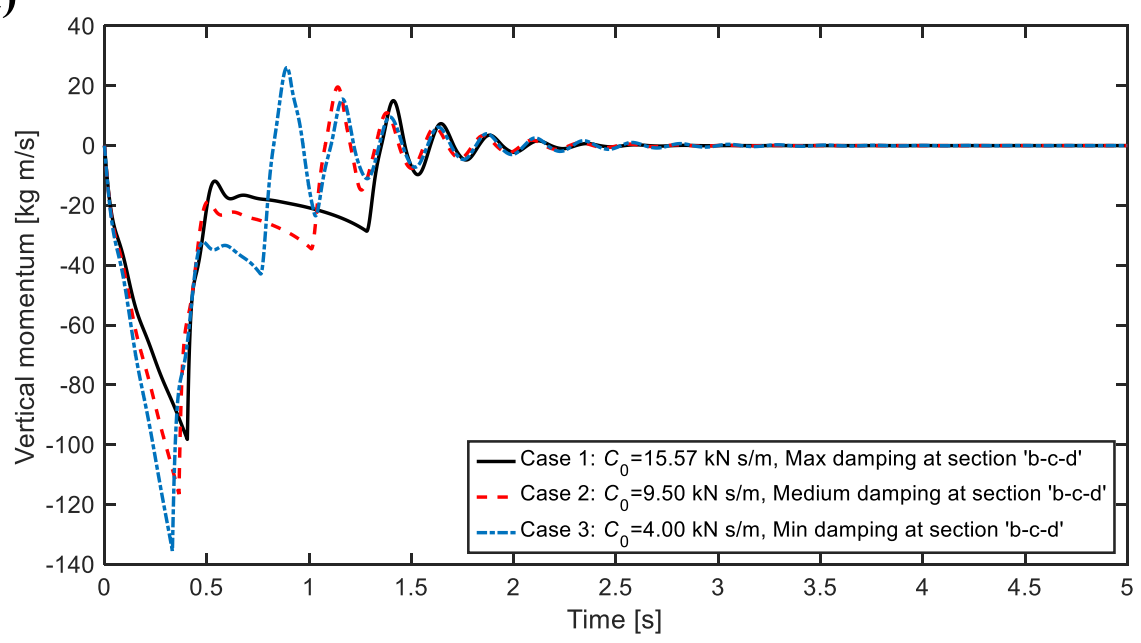

(b)

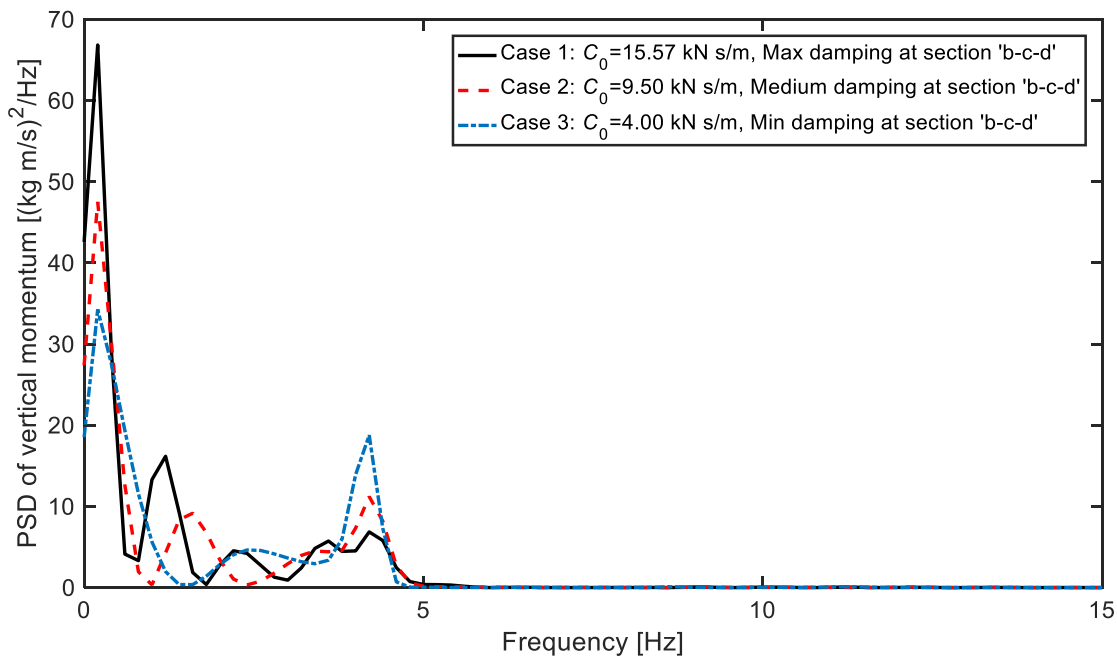

Fig. 16 Instantaneous vertical momentum (a) and PSD of the vertical momentum (b) of the pantograph when the pantograph is lowered 
(a)

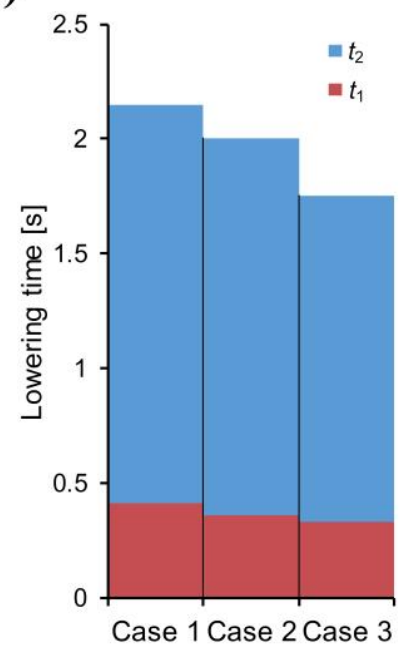

(b)

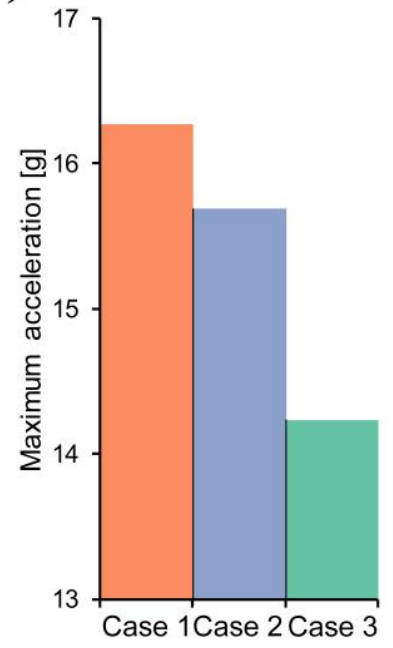

(c)

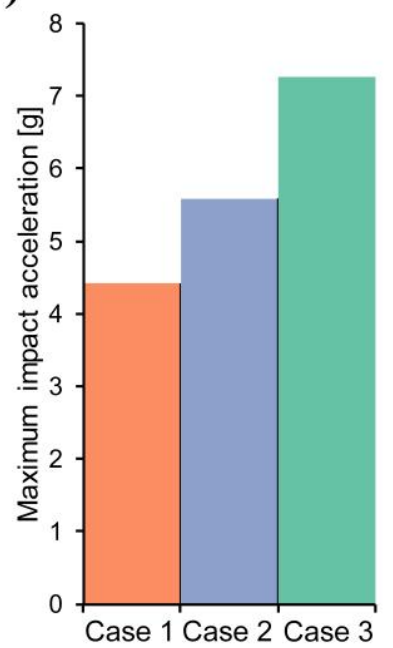

Fig. 17 Lowering time in terms of $t_{1}$ and $t_{2}$ (a), maximum acceleration (b) and maximum impact acceleration (c) of the pantograph

Figs. 17(b) and (c) show that the higher level of damping in section "b-c-d" of the damper corresponds to the larger maximum acceleration and smaller maximum impact acceleration of the pantograph. In other words, the speed of the pantograph with high-level damping (Case 1) is quickly reduced, and the pantograph is more softly dropped on the base frame, but a longer total lowering time (Fig. 17(a)) is induced by the high-level damping.

Therefore, from the viewpoint of lowering performance, the damping coefficient $C_{0}$ in section "a-b" of the damper has no obvious effect on the lowering time of the pantograph, whereas the nonlinear damping characteristics in section "b-c-d" of the damper, which are described by the second item in Eq. (41), have dominating effects on the total lowering time, maximum acceleration and maximum impact acceleration of the pantograph. Thus, within the constraint of the total lowering time, increasing the damping characteristics in section "b-c-d" will obviously improve the lowering performance of the pantograph.

\section{Concluding remarks}

(1) A new simplified-parametric model was proposed to describe the nonlinear displacement-dependent damping characteristics of the railway pantograph hydraulic damper and validated by experimental results. A full mathematical model of the pantograph-catenary system, which incorporated the new pantograph damper model, was established to simulate the effect of the damping characteristics on the pantograph dynamics, which includes the raising, holding and lowering performance of the pantograph.

(2) Large $F_{\text {const }}$ and $C_{0}$ in the pantograph damper model have three benefits: increased response quality of the pantograph when the pantograph is raised; avoidance of excessive impact between the pan-head and the catenary; and improved pantograph-catenary contact quality by increasing the percentage of normal contact forces and reducing the percentage of extreme contact forces. Let alone, a large $C_{0}$ has no obvious 
effect on the lowering time of the pantograph; thus, in engineering design, $C_{0}$ and $F_{\text {const }}$ should not be too small or zero.

(3) The nonlinear damping characteristics described by the second item in the new damper model have dominating effects on the total lowering time, maximum acceleration and maximum impact acceleration of the pantograph. Thus, within the constraint of total lowering time, increasing the second item damping characteristics of the damper will obviously improve the lowering performance of the pantograph and reduce excessive impact between the pantograph and its base frame.

(4) The proposed concise pantograph hydraulic damper model appears to be more complete and accurate than the previous single-parameter model, so it is more useful in pantograph-catenary dynamics simulations and further parameter optimizations. The obtained simulation results are also useful and instructive for optimal specification of pantograph hydraulic dampers. However, this work was performed by neglecting the performance and time delay of the pneumatic actuating system, so it will be interesting to incorporate the pneumatic system dynamics in the next study.

\section{Acknowledgement}

The authors thank financial support from the National Natural Science Foundation of China (Grant No. 11572123), the Joint Funds of Hunan Provincial Natural Science Foundation and Zhuzhou Science and Technology Bureau (Grant No. 2017JJ4015), the State Key Laboratory of Traction Power in Southwest Jiaotong University (Grant No. TPL1609) and the Research Fund for High-level Talent of Dongguan University of Technology (Project No. G200906-43).

\section{Appendix:}

Parameters and values in the pantograph-catenary dynamics modelling and simulation

\begin{tabular}{|c|c|c|c|}
\hline Notation (Unit) & Description & Value & Remarks \\
\hline$m_{1}(\mathrm{~kg})$ & Coupling rod mass & 3.90 & \\
\hline$J_{1}\left(\mathrm{~kg} \mathrm{~m}^{2}\right)$ & Coupling rod moment of inertia & 1.88 & \\
\hline$l_{1}(\mathrm{~m})$ & Coupling rod length & 1.20 & \\
\hline$l_{\mathrm{m} 1}(\mathrm{~m})$ & $\begin{array}{l}\text { Length from the center of gravity of the coupling rod to } \\
\text { joint } A\end{array}$ & $6.03 \mathrm{E}-001$ & \\
\hline$\theta_{2}\left(^{\circ}\right)$ & Angle from the coupling rod to level & Variable & \\
\hline$l_{2}(\mathrm{~m})$ & Length of connecting rod $B C$ & $3.40 \mathrm{E}-001$ & \\
\hline$\theta_{1}\left({ }^{\circ}\right)$ & Angle from the connecting rod $B C$ to level & Variable & \\
\hline
\end{tabular}




\begin{tabular}{|c|c|c|}
\hline$m_{3}(\mathrm{~kg})$ & Lower arm mass & $2.10 \mathrm{E}+001$ \\
\hline$J_{3}\left(\mathrm{~kg} \mathrm{~m}^{2}\right)$ & Lower arm moment of inertia & $1.75 \mathrm{E}+001$ \\
\hline$l_{3}(\mathrm{~m})$ & Lower arm length & 1.58 \\
\hline$l_{\mathrm{m} 3}(\mathrm{~m})$ & $\begin{array}{l}\text { Length from the center of gravity of the lower arm to } \\
\text { joint } D\end{array}$ & 7.93E-001 \\
\hline$\alpha\left(^{\circ}\right)$ & Rising angle of the lower arm (pantograph) & Variable \\
\hline$h_{0}(\mathrm{~m})$ & Vertical distance of joints $A$ and $D$ & $1.30 \mathrm{E}-001$ \\
\hline$l_{0}(\mathrm{~m})$ & Horizontal distance of joints $A$ and $D$ & $7.20 \mathrm{E}-001$ \\
\hline$m_{4}(\mathrm{~kg})$ & Upper arm mass & $1.60 \mathrm{E}+001$ \\
\hline$J_{4}\left(\mathrm{~kg} \mathrm{~m}^{2}\right)$ & Upper arm moment of inertia & $2.02 \mathrm{E}+001$ \\
\hline$l_{4}(\mathrm{~m})$ & Upper arm length & 1.95 \\
\hline$l_{\mathrm{m} 4}(\mathrm{~m})$ & $\begin{array}{l}\text { Length from the center of gravity of the upper arm to } \\
\text { joint } C\end{array}$ & $9.14 \mathrm{E}-001$ \\
\hline$\beta\left(\left(^{\circ}\right)\right.$ & Angle from the connecting rod $B C$ to upper arm & $1.15 \mathrm{E}+001$ \\
\hline$y_{\mathrm{e}}(\mathrm{m})$ & Height of joint $E$ & Variable \\
\hline$m_{\mathrm{h}}(\mathrm{kg})$ & Pan-head mass & 5.00 \\
\hline$k_{\mathrm{h}}(\mathrm{N} / \mathrm{m})$ & Equivalent stiffness of the pan-head suspension & $7.60 \mathrm{E}+003$ \\
\hline$c_{\mathrm{h}}(\mathrm{N} / \mathrm{m})$ & $\begin{array}{l}\text { Equivalent damping coefficient of the pan-head } \\
\text { suspension }\end{array}$ & $5.00 \mathrm{E}+001$ \\
\hline$l_{\mathrm{h}}(\mathrm{m})$ & Height between the collector and joint $E$ & $1.00 \mathrm{E}-001$ \\
\hline$y_{\mathrm{h}}(\mathrm{m})$ & Height of the pantograph collector & Variable \\
\hline$y_{\mathrm{c}}(\mathrm{m})$ & Height of the catenary & 1.70 \\
\hline$L_{\mathrm{c}}(\mathrm{m})$ & Span length of the catenary & $6.30 \mathrm{E}+001$ \\
\hline$L_{\mathrm{d}}(\mathrm{m})$ & Dropper interval & 9.00 \\
\hline$k_{\mathrm{c}}(\mathrm{N} / \mathrm{m})$ & Catenary stiffness & Variable \\
\hline$k_{0}(\mathrm{~N} / \mathrm{m})$ & Static stiffness of the catenary & $3.6845 \mathrm{E}+003$ \\
\hline$a_{1}$ & Coefficient & 4.665E-001 \\
\hline$a_{2}$ & Coefficient & $8.32 \mathrm{E}-002$ \\
\hline$a_{3}$ & Coefficient & 2.603E-001 \\
\hline$a_{4}$ & Coefficient & $-2.801 \mathrm{E}-001$ \\
\hline
\end{tabular}




\begin{tabular}{|c|c|c|c|}
\hline$a_{1}$ & Coefficient & $-3.364 \mathrm{E}-001$ & \\
\hline$F_{\mathrm{c}}(\mathrm{N})$ & Pantograph-catenary contact force & Variable & \\
\hline$v(\mathrm{~km} / \mathrm{h})$ & Vehicle speed & $2.00 \mathrm{E}+002$ & \\
\hline$L$ & Lagrangian function & Function & \\
\hline$T(\mathrm{~J})$ & Kinetic energy of the framework & Variable & \\
\hline$U(\mathrm{~J})$ & Potential energy of the framework & Variable & \\
\hline$G_{\mathrm{F}}(\mathrm{N} \mathrm{m})$ & Generalized force & Variable & \\
\hline$J_{\mathrm{f}}\left(\mathrm{kg} \mathrm{m}^{2}\right)$ & Equivalent moment of inertia of the framework & Variable & \\
\hline$U_{\mathrm{f}}\left(\mathrm{N} \mathrm{s}^{2} / \mathrm{m}\right)$ & Coefficient of $\dot{y}_{\mathrm{e}}^{2}$ in dynamic model of the framework & Variable & \\
\hline$F_{\mathrm{f}}(\mathrm{N} \mathrm{m})$ & Equivalent generalized force of the framework & Variable & \\
\hline$M_{\alpha}(\mathrm{N} \mathrm{m})$ & Uplift moment & Variable & \\
\hline$F_{\mathrm{u}}(\mathrm{N})$ & Static uplift force & $7.00 \mathrm{E}+001$ & \\
\hline$C_{\mathrm{f}}(\mathrm{N} \mathrm{s} / \mathrm{m})$ & Equivalent damping coefficient of the framework & Variable & \\
\hline$F_{\mathrm{d}}(\mathrm{N})$ & Damping force of the hydraulic damper & Variable & \\
\hline$g\left(\mathrm{~m} / \mathrm{s}^{2}\right)$ & Acceleration of gravity & 9.80 & \\
\hline$l(\mathrm{~m})$ & Length of the connection rod $D P$ & $1.80 \mathrm{E}-001$ & \\
\hline$x_{\mathrm{d}}(\mathrm{m})$ & Horizontal distance between point $P$ and joint $N$ & $3.50 \mathrm{E}-001$ & \\
\hline$y_{\mathrm{d}}(\mathrm{m})$ & Vertical distance between joints $D$ and $N$ & 0.00 & $\begin{array}{l}\text { Joints } D \text { and } \\
N \text { are on the } \\
\text { same level }\end{array}$ \\
\hline$s(\mathrm{~m})$ & Instantaneous length of the hydraulic damper & Variable & \\
\hline$\gamma\left({ }^{\circ}\right)$ & Angle from the connection rod $D P$ to lower arm & $5.56 \mathrm{E}+001$ & \\
\hline$s_{0}(\mathrm{~m})$ & $\begin{array}{l}\text { Hydraulic damper length when the pantograph is } \\
\text { completely raised }\end{array}$ & $3.65 \mathrm{E}-001$ & \\
\hline$x(t)(\mathrm{m})$ & Instantaneous displacement of the hydraulic damper & Variable & \\
\hline$k_{1}-k_{13}$ & Coefficients & Variable & $\begin{array}{l}\text { The unit } \\
\text { depends on } \\
\text { concrete } \\
\text { meaning of } \\
\text { the coefficient }\end{array}$ \\
\hline$t(\mathrm{~s})$ & Time & Variable & \\
\hline$A_{\mathrm{c}}\left(\mathrm{m}^{2}\right)$ & $\begin{array}{l}\text { Pressure action area of the piston during the extension } \\
\text { stroke of the damper }\end{array}$ & Variable & \\
\hline
\end{tabular}




\begin{tabular}{|c|c|c|c|}
\hline$A_{\mathrm{f}}\left(\mathrm{m}^{2}\right)$ & $\begin{array}{l}\text { Cross-section area of the orifices in the rod for fluid } \\
\text { outflow }\end{array}$ & Variable & \\
\hline$A_{1}-A_{n}\left(\mathrm{~m}^{2}\right)$ & $\begin{array}{l}\text { Changeable cross-section area of the orifices in the rod } \\
\text { for fluid inflow }\end{array}$ & Variable & $\begin{array}{l}n=1,2, \ldots 6 \text { in } \\
\text { this work }\end{array}$ \\
\hline$A_{\mathrm{x}}\left(\mathrm{m}^{2}\right)$ & $\begin{array}{l}\text { Pressure action area of the piston during the } \\
\text { compression stroke of the damper }\end{array}$ & Variable & \\
\hline$C_{\text {com }}(\mathrm{N} \mathrm{s} / \mathrm{m})$ & Damping coefficient of the damper during compression & Variable & \\
\hline$C_{\mathrm{d} 1}$ & Discharge coefficient of the orifice & $7.20 \mathrm{E}-001$ & \\
\hline$C_{\mathrm{d} 2}$ & Discharge coefficient of the shim-stack valve & $6.10 \mathrm{E}-001$ & \\
\hline$C_{\mathrm{e}}$ & Equivalent-pressure correction factor & $3.15 \mathrm{E}-001$ & FEA identified \\
\hline$C_{\text {ext }}(\mathrm{N} \mathrm{s} / \mathrm{m})$ & Damping coefficient of the damper during extension & Variable & \\
\hline$C_{\mathrm{w}}\left(\mathrm{m}^{6} / \mathrm{N}\right)$ & Deflection coefficient of the shim & Variable & \\
\hline$C_{0}(\mathrm{~N} \mathrm{~s} / \mathrm{m})$ & $\begin{array}{l}\text { Initial damping coefficient of the damper during } \\
\text { extension }\end{array}$ & Variable & \\
\hline$D(\mathrm{~m})$ & Piston diameter & $3.60 \mathrm{E}-002$ & \\
\hline$E(\mathrm{~Pa})$ & Elastic modulus of the shim & $2.00 \mathrm{E}+011$ & \\
\hline$F_{\text {const }}(\mathrm{N})$ & Damping force of the damper during compression & Variable & \\
\hline$P(\mathrm{~Pa})$ & Instantaneous working pressure of the damper & Variable & \\
\hline$P_{\mathrm{i}}(\mathrm{Pa})$ & Instantaneous pressure in the hollow passage of the rod & Variable & \\
\hline$Q_{\text {work }}\left(\mathrm{m}^{3} / \mathrm{s}\right)$ & Instantaneous working flow of the damper & Variable & \\
\hline$d(\mathrm{~m})$ & Rod diameter & $1.58 \mathrm{E}-002$ & \\
\hline$d_{0}(\mathrm{~m})$ & Diameter of the orifice in the inner tube & $6.00 \mathrm{E}-004$ & \\
\hline$d_{1}(\mathrm{~m})$ & Diameter of the orifice in the rod for fluid inflow & $1.10 \mathrm{E}-003$ & \\
\hline$d_{2}(\mathrm{~m})$ & Diameter of the orifice in the rod for fluid outflow & $1.20 \mathrm{E}-003$ & \\
\hline$d_{3}(\mathrm{~m})$ & Diameter of the orifice in the rod for fluid outflow & $1.10 \mathrm{E}-003$ & \\
\hline$d_{4}(\mathrm{~m})$ & Diameter of the orifice in the rod for fluid outflow & $1.10 \mathrm{E}-003$ & \\
\hline$h_{1}-h_{\mathrm{n}}(\mathrm{m})$ & Thickness of the shims in a shim-stack & $5.00 \mathrm{E}-004$ & \\
\hline$r_{\mathrm{s}}(\mathrm{m})$ & Outer radius of the shim & 8.00E-003 & \\
\hline$s_{\mathrm{a}}(\mathrm{m})$ & Displacement amplitude of the damper & $5.00 \mathrm{E}-002$ & \\
\hline$s_{1}(\mathrm{~m})$ & Distance from the first orifice in the rod to point $\left(0, s_{\mathrm{a}} / 2\right)$ & $2.10 \mathrm{E}-002$ & \\
\hline$\Delta s_{1}(\mathrm{~m})$ & Orifice interval & $1.40 \mathrm{E}-003$ & \\
\hline$\Delta s_{2}(\mathrm{~m})$ & Orifice interval & $3.20 \mathrm{E}-003$ & \\
\hline$\rho\left(\mathrm{kg} / \mathrm{m}^{3}\right)$ & Oil density & $8.75+002$ & \\
\hline
\end{tabular}




\section{References}

1. Zhang, W.H.: The development of China's high-speed railway systems and a study of the dynamics of coupled systems in high-speed trains. IMechE, Part F: J. Rail \& Rapid Transit. 228(4), 367-377 (2014)

2. Mellado, A.C., Gómez, E., Viñolas, J.: Advances on railway yaw damper characterisation exposed to small displacements. Int. J. Heavy Veh. Syst. 13(4), 263-280 (2006)

3. Alonso, A., Giménez, J.G., Gomez, E.: Yaw damper modelling and its influence on railway dynamic stability. Veh. Syst. Dyn. 49(9), 1367-1387 (2011)

4. Wang, W.L., Yu, D.S., Huang, Y., Zhou, Z., Xu, R.: A locomotive's dynamic response to in-service parameter variations of its hydraulic yaw damper. Nonlinear Dyn. 77(4), 1485- 1502 (2014)

5. Wang, W.L., Zhou, Z.R., Yu, D.S., Qin, Q.H., Iwnicki, S.: Rail vehicle dynamic response to the nonlinear physical in-service model of its secondary suspension hydraulic dampers. Mechanical Systems and Signal Processing. 95, 138-157 (2017)

6. Oh, J.S., Shin, Y.J., Koo, H.W., Kim, H.C., Park, J., Choi, S.B.: Vibration control of a semi-active railway vehicle suspension with magneto-rheological dampers. Advances in Mechanical Engineering. 8(4), 1-13 (2016)

7. Stein, G.J., Múčka, P., Gunston, T.P.: A study of locomotive driver's seat vertical suspension system with adjustable damper. Veh. Syst. Dyn. 47(3), 363-386 (2009)

8. Croft, B.E., Jones, C.J.C., Thompson, D.J.: Modelling the effect of rail dampers on wheel-rail interaction forces and rail roughness growth rates. J. Sound Vib. 323, 17-32 (2009)

9. Pombo, J., Ambrósio, J.: Influence of pantograph suspension characteristics on the contact quality with the catenary for high speed trains. Computers and Structures. 110-111, 32-42 (2012)

10. Lopez-Garcia, O., Carnicero, A., Maroño, J.L.: Influence of stiffness and contact modelling on catenary-pantograph system dynamics. J. Sound Vib. 299(4), 806-821 (2007)

11. Kim, J.W., Chae, H.C., Park, B.S., Lee, S.Y., Han, C.S., Jang, J.H.: State sensitivity analysis of the pantograph system for a high-speed rail vehicle considering span length and static uplift force. J. Sound Vib. 303(3-5), 405-427 (2007)

12. Cho, Y.H.: Numerical simulation of the dynamic responses of railway overhead contact lines to a moving pantograph considering a nonlinear dropper. J. Sound Vib. 315, 433-454 (2008)

13. Cho, Y.H., Lee, K., Park, Y., Kang, B., Kim, K.: Influence of contact wire pre-sag on the dynamics of pantograph - railway catenary. Int. J. Mech. Sci. 52(11), 1471-1490 (2010)

14. Bautista, A., Montesinos, J., Pintado, P.: Dynamic interaction between pantograph and rigid overhead lines using a coupled FEM - multibody procedure. Mechanism and Machine Theory. 97, 100-111 (2016)

15. Gregori, S., Tur, M., Nadal, E., Aguado, J.V., Fuenmayor, F.J., Chinesta, F.: Fast simulation of the pantograph - catenary dynamic interaction. Finite Elements in Analysis and Design. 129, 1-13 (2017)

16. Zhang, W.H., Liu, Y., Mei, G.M.: Evaluation of the coupled dynamical response of a pantograph-catenary system: contact force and stresses. Veh. Syst. Dyn. 44(8), 645-658 (2006)

17. Benet, J., Cuartero, N., Cuartero, F., Rojo, T., Tendero, P., Arias, E.: An advanced 3D-model for the study and simulation of the pantograph catenary system. Transportation Research Part C. 36, 138-156 (2013)

18. Song, Y., Ouyang, H.J., Liu, Z.G., Mei, G.M., Wang, H.R., Lu, X.B.: Active control of contact force for high-speed railway pantograph-catenary based on multi-body pantograph model. Mechanism and Machine Theory. 115, 35-59 (2017)

19. Zhou, N., Zhang, W.H.: Investigation on dynamic performance and parameter optimization design of pantograph and catenary 
system. Finite Elements in Analysis and Design. 47(3), 288-295 (2011)

20. Ma, G.N.: A study on the pantograph-catenary system. Master's degree thesis, South-west Jiaotong University (2009) (in Chinese)

21. Lee, J.H., Kim, Y.G., Paik, J.S., Park, T.W.: Performance evaluation and design optimization using differential evolutionary algorithm of the pantograph for the high-speed train. J. Mech. Sci. Tech. 26(10), 3253-3260 (2012)

22. Ambrósio, J., Pombo, J., Pereira, M.: Optimization of high-speed railway pantographs for improving pantograph-catenary contact. Theoretical and Applied Mechanics Letters. 3(1), 013006 (2013)

23. Kim, J.W., Yu, S.N.: Design variable optimization for pantograph system of high-speed train using robust design technique. Int. J. Precis. Eng. Man. 14(2), 267-273 (2013)

24. Zhang, W.H.: Dynamic Simulation of Railway Vehicles. China Railway Publishing House, Beijing (2006) (in Chinese)

25. Guo, J.B.: Stable current collection and control for high-speed locomotive pantograph. Ph.D. thesis, Beijing Jiaotong University (2006) (in Chinese)

26. Wang, W.L., Zhou, Z.R., Cao, X.C., Iwnicki, S.: Physical modelling the displacement-dependent nonlinear characteristics of a high-speed rail pantograph hydraulic damper. Int. J. Eng. Sci. (Submitted)

27. Chinese National Standard: Railway applications - Rolling stock - Pantographs - Characteristics and tests - Part 1: Pantographs for mainline vehicles, GB/T 21561.1-2008 (2008) (in Chinese) 